\title{
Comparison of different water supply risk management tools for irrigators: option contracts and insurance
}

\author{
Dolores Rey $^{\mathrm{a}, \mathrm{b} *}$, Alberto Garrido ${ }^{\mathrm{a}}$, Javier Calatrava ${ }^{\mathrm{c}}$ \\ ${ }^{a}$ CEIGRAM, Universidad Politécnica de Madrid. Senda del Rey, 13. ETSI Agrónomos, Campos \\ de Prácticas, 28040, Madrid (Spain). alberto.garrido@upm.es. \\ ${ }^{b}$ Cranfield Water Science Institute, Cranfield University, MK43 OAL, Cranfield, Bedfordshire \\ (UK).d.reyvicario@cranfield.ac.uk \\ ${ }^{c}$ Universidad Politécnica de Cartagena. Paseo de Alfonso XIII 48. 30203, Cartagena, Murcia \\ (Spain).j.calatrava@upct.es
}

\begin{abstract}
Irrigators must cope with the risk of not having enough water to meet crop demands. There are different tools for managing this risk, including water market mechanisms and insurance. Given the choice, farmers will opt for the tool that offers the greatest positive change in expected utility. This paper presents a theoretical assessment of farmers' expected utility for two different water option contracts and a drought insurance policy. We analyze the conditions that determine farmers' preferences for these instruments and perform a numerical application to a water-stressed Spanish region. Results show that farmers' willingness to pay for the considered risk management tools are greater than the preliminary estimates of these instruments costs. This suggests that option contracts and insurance may help farmers manage water supply availability risks.
\end{abstract}

Keywords: drought insurance, expected utility, water supply option contract, uncertainty, Spain, water markets.

\footnotetext{
${ }^{*}$ Corresponding author
} 
Abbreviations: CARA (constant absolute risk aversion); DARA (decreasing absolute risk aversion); MGF (moment generating function); PDF (probability density function); CV (coefficient of variation), WTP (willingness to pay). 


\title{
Comparison of different water supply risk management tools for irrigators: option contracts and insurance
}

\begin{abstract}
Irrigators must cope with the risk of not having enough water to meet crop demands. There are different tools for managing this risk, including water market mechanisms and insurance. Given the choice, farmers will opt for the tool that offers the greatest positive change in expected utility. This paper presents a theoretical assessment of farmers' expected utility for two different water option contracts and a drought insurance policy. We analyze the conditions that determine farmers' preferences for these instruments and perform a numerical application to a water-stressed Spanish region. Results show that farmers' willingness to pay for the considered risk management tools are greater than the preliminary estimates of these instruments costs. This suggests that option contracts and insurance may help farmers manage water supply availability risks.
\end{abstract}

Keywords: drought insurance, expected utility, water supply option contract, uncertainty, Spain, water markets.

Abbreviations: CARA (constant absolute risk aversion); DARA (decreasing absolute risk aversion); MGF (moment generating function); PDF (probability density function); CV (coefficient of variation), WTP (willingness to pay).

\section{Introduction}

Irrigators face the risk of not having enough water to meet crop demands. There are a number of strategies for confronting this risk. Farmers can apply on-farm strategies to reduce vulnerability, share the risk with an external agent (Cummins and Thompson 2002; FAO 2003; Hardaker et al. 2004; Sivakumar and Motha 2007; Garrido and Gómez-Ramos 2009), 
or combine internal and external instruments. Of all the existing tools that could help irrigators manage this risk, this paper focuses on water supply option contracts and drought insurance.

The possibility of trading water rights may lead to a reduction in the water availability risk faced by farmers (Calatrava and Garrido 2005a, 2005b; Bjornlund 2006; Lefebvre 2011). Option contracts are one type of derivative contract that gives the holder the right (not the obligation) to buy or sell the underlying asset (Williamson et al. 2008; Cui and Schreider 2009; Cheng et al. 2011). Water option contracts give option holders protection against the risk of not having enough water for their activity (irrigation in the case of farmers).

Insurance provides compensation for losses that occur with relatively low frequency and whose probability and actual damage can be evaluated (Garrido et al. 2012a). Index insurance has been proposed to deal with water scarcity in several countries, including Mexico (Zeuli and Skeest 2005; Leiva and Skees 2008) and New South Wales (Australia) (Brown and Carriquiry 2007). In this paper, the proposed insurance will provide a monetary compensation when the volume of irrigation water to which a farmer is entitled is reduced and falls short of meeting the average crop water demand. Unlike option contracts, an insurance policy transfers the water supply risk outside the water and agricultural markets.

While both instruments (water option contracts and drought insurance) aim at protecting irrigators from water supply availability risks, they have different features and prerequisites. Of the available alternatives, farmers will choose the risk management tools that are perceived to improve their utility. The literature on agricultural water supply risks has not theoretically analyzed and compared different mechanisms. This is one of the main objectives of this paper. 
We develop a theoretical framework to evaluate farmers' willingness to pay (WTP) and to ascertain agents' hypothetical preference ordering for different water supply risk management instruments. We use the expected utility theory approach to compare drought insurance and option contracts and draw some conclusions about the design parameters that may make one mechanism more attractive than the other. We consider three different situations: no water supply risk management tool, a water option contract (two different types), and a drought insurance. We also provide preliminary evaluations of the costs of, and farmers' potential willingness to pay for these instruments.

Both drought insurance and option contracts are being considered or have been actually designed and structured, though not yet used, in Spain. The developed theoretical framework is applied to an irrigation district in Southeast Spain to obtain some numerical results that show farmers' potential WTP for the proposed instruments. These results are compared to others reported in previous works on different water supply risk management tools also applied to Spain (Tobarra 2008; Rigby et al. 2010; Mesa-Jurado et al. 2012; PérezBlanco and Gómez 2012, 2013).

The paper is organized as follows. Section 2 presents the theoretical framework, calculating farmers' expected utility, the risk premium and the cost of each instrument. Section 3 includes an analysis of farmers' preferences for the proposed instruments. Section 4 presents the application of the theoretical model to irrigators in one of the most arid and most efficient agricultural areas in Spain. Section 5 provides a discussion of the results. Finally, Section 6 presents some conclusions of this analysis, highlighting the importance of these risk management tools for agriculture. Most of the mathematical derivations are presented in the appendices at the end of the paper to make the body of the paper easier to follow. 


\section{Theoretical framework}

According to expected utility theory, a decision maker chooses between risky or uncertain prospects by comparing their expected utility values (Mongin 1997). Given a choice, an agent will choose the alternative with higher expected utility.

We assume that the farmers' expected utility (EU) depends on their uncertain profit $(\tilde{\pi})$. As irrigators, farmers' profit will be a function of their seasonal water availability $(\widetilde{w})$, which follows a probability distribution function, $f(w)$.

$$
E U(\tilde{\pi})=\int U(\pi(w)) f(w) d w
$$

Farmers would choose to use an instrument, $i$, if their expected utility is greater than it would be without this instrument $\left(E U_{0}(\tilde{\pi})\right)$ :

$$
E U_{i}(\tilde{\pi})-E U_{0}(\tilde{\pi})>0
$$

Even conceding that the EU framework has been consistently discredited by empirical work (Kahneman and Tversky 1979; Just and Peterson 2010), it still provides a valid approach for discriminating among risk management instruments whose outcomes are not extremely different in both their second and third moments, such as the instruments considered in this paper.

We make some assumptions to simplify the mathematics of the theoretical analysis and facilitate the comparison of the considered risk management tools. First, although several studies have shown that farmers mainly exhibit decreasing absolute risk aversion (DARA) (Hardaker 2000; Gómez-Limón et al. 2002; OECD 2009), we assume a constant absolute risk aversion (CARA), in particular an exponential utility function $\left(U(\pi)=1-e^{-r \pi}\right)$. Assuming a DARA utility function, such as the logarithmic or the power function, results in integrals that have no analytical solution for the most common asymmetric probability density 
functions that are suitable to model $f(w)$ (gamma, lognormal, beta, Weibull), except for the exponential function. However, the exponential function has very rigid properties (mean, variance, kurtosis) that are not suitable for this analysis. For our purpose of comparing different risk management instruments, we give precedence to the analytical convenience of using a CARA utility function, taking into account that the considered range of outcomes of $\tilde{\pi}$ is not very wide (see Calatrava and Garrido 2005b; Garrido 2007) and that farmers' wealth (land and capital values) is invariant to the choice of instrument. Several authors have used the same assumption before (Cerdá and Quiroga 2008; Garrido and Zilberman 2008; Quiroga et al. 2011). In the empirical part of the paper (Section 4), we compare the results of applying DARA and CARA.

Second, we assume a linear restricted profit function (dependent on $\widetilde{w}$ ). This assumption is acceptable in cases where water is used in Leontief production functions, each activity has fixed proportion of inputs and farmers' short-term option is to change activities (crops) rather than to look for new production methods. This really is the case in many irrigated areas where water rather than irrigable land is the limiting input, water applications to crops are finely controlled and changes of water availability result in changes in crop patterns and irrigated area instead of changes in water applications.

Lastly, we assume that farmers' water availability follows a gamma distribution function. This function has a simple moment generating function ${ }^{1}$ (MGF) that facilitates calculation and, together with the previous assumptions, provides a convenient analytical approach (Collender and Zilberman 1985; Garrido and Zilberman 2008). The gamma is bounded on the left, but unbounded on the right. We assume a truncation on the right tail (at $\bar{w})$. This excluded right tail of the distribution represents unlimited and unneeded water availability levels. 
Based on these assumptions and applying the expected utility theory, we have obtained the mathematical expressions of farmers' expected utility and risk premium for the different cases.

\subsection{Expected utility function without a water supply risk management tool}

In this case, farmers' total water availability would be their water allotment $(\widetilde{w})$. We use a linear restricted profit function $\left(\tilde{\pi}_{0}(w)\right)$. We take into account neither the costs associated with the farming activity nor income ${ }^{2}$.

$$
\tilde{\pi}_{0}(w)=a+b \widetilde{w}
$$

where $a$ is the net benefit of agriculture, independent of water availability, and $b$ is the marginal value or marginal profit of water (net of price) ${ }^{3}$. The CARA exponential utility function for this case is

$$
U\left(\tilde{\pi}_{0}\right)=1-e^{-r \widetilde{\pi}_{0}}=1-e^{-r(a+b \widetilde{w})}
$$

where $r$ is farmers' absolute risk aversion coefficient. Farmers' expected utility can be expressed as (see Appendix A for the entire calculation):

$$
E U_{0}(\widetilde{\pi})=\int_{0}^{\bar{w}} U(\tilde{\pi}) f(w) d w=\int_{0}^{\bar{w}}\left[1-e^{-r(a+b w)}\right] f(w) d w=1-e^{-r a} M G F_{w}(-r b),
$$

where $\bar{w}$ is the maximum water availability for the farmer, zero being the minimum, and $M G F_{w}(-r b)$ is the moment generating function of the variable $\widetilde{w}$ of order $(-r b)$. As explained above, we assume that variable $\widetilde{w}$ follows a gamma distribution, which has a rather simple MGF:

$$
M G F_{w}(-r b)=\left(1+\frac{r b}{\lambda}\right)^{-\alpha}
$$


where $\lambda$ and $\alpha$ are parameters of the gamma function; with mean $\alpha / \lambda$ and variance $\alpha / \lambda^{2}$. From Equation (5) it is clear that $M G F_{w}(-r b)$ is the disutility resulting from unstable profit $(\tilde{\pi})$. It decreases with the marginal productivity of water $\left(\frac{\partial M G F_{w}(-r b)}{\partial b}<0\right)$ and increases with water supply variance if the average water supply is constant $\left.\left.\left(\frac{\partial M G F_{w}(-r b)}{\partial \sigma_{w}^{2}}\right)\right|_{w^{e}}>0\right)$.

\subsection{Potential water supply risk management tools}

In this paper, we consider three different water supply risk management tools for irrigators (two different option contracts and drought insurance). For readability, only the theoretical model for one of the option contracts is presented in detail. Based on this mathematical calculation, the risk premium for the other two tools is briefly presented. We present the entire mathematical analyses for these instruments in Appendices B through E.

\subsubsection{Option contract (a)}

This option contract allows farmers (option holders) whose yearly water allotment $(\widetilde{w})$ is below a given threshold or guaranteed level $\left(w_{g}\right)$ to exercise the option when an external condition (trigger) is also met and receive the remaining water volume to reach the guaranteed level $\left(w_{g}-\widetilde{w}\right)$, paying the exercise price to the seller.

A farmer that decides to sign an option contract has to pay a premium $(P)$ to the seller for the right to purchase the optioned water volume at the maturity date if needed. The premium represents the value of the flexibility gained by the buyer from postponing the decision to purchase water (Hansen et al. 2006); and it must compensate the seller for giving away part of his water allotment.

The farmer would only be able to exercise the option and acquire the optioned volume when two different trigger conditions are met: the buyer's water availability is lower than $w_{g}$, 
and the water stock $(S)$ in the reservoir which stores the seller's water allotment is greater than a pre-established limit $k^{4}$. As both conditions are related to water availability, we assume they are stochastically dependent. Thus, the probability of exercising the option can be modeled as a joint probability distribution. For the rest of the paper, this probability is denoted by $Z$. When either of these two conditions is not met, the option contract cannot be exercised $($ prob $=1-Z)$.

The farmers' profit function depends in this case on whether the conditions related to the option contract are met (subscript $a$ denotes option contract of type $a$ ):

$$
\begin{gathered}
\tilde{\pi}_{o p t_{a}}(w)=a+b \widetilde{w}-P_{o p t_{a}} \quad \text { if } \widetilde{w} \geq w_{g} \\
\tilde{\pi}_{o p t_{a}}(w)=\tilde{\varphi}\left(a+b w_{g}-P_{o p t_{a}}-P_{e}\left(w_{g}-\widetilde{w}\right)\right)+(1-\widetilde{\varphi})\left(a+b \widetilde{w}-P_{o p t_{a}}\right) \quad \text { if } \widetilde{w}<w_{g} .
\end{gathered}
$$

$P_{o p t_{a}}$ is the option premium. $\varphi$ is a binomial variable $(0,1)$, with a probability $Z$ of being 1 , so the option is exercised. $P_{e}$ is the exercise price or strike price ${ }^{5}$.

The farmers' expected utility function with this option contract is (see Appendix B.1)

$$
\begin{gathered}
E U_{o p t_{a}}(\tilde{\pi})=1-e^{-r\left(a-P_{o p t}\right)} M G F_{w}(-r b)-Z e^{-r\left(a+b w_{g}-P_{o p t_{a}}-P_{e} w_{g}\right)} L I M G F_{w}\left(-r P_{e}\right) \\
+Z e^{-r\left(a-P_{o p t_{a}}\right)} \operatorname{LIMGF}_{w}(-r b),
\end{gathered}
$$

where LIMGF is the lower incomplete moment generating function ${ }^{6}$ of $\widetilde{w}$.

The maximum premium value that makes the contract attractive to farmers (i.e., the risk premium, $R_{\text {opt }}$ ) is the result of making the farmers' expected utility with and without the option contract equal (see Appendix B.2 for the entire mathematical derivation).

$$
E U_{0}(\tilde{\pi})=E U_{o p t_{a}}(\tilde{\pi})
$$




$$
R_{o p t_{a}}=\frac{1}{r} \ln \left(\frac{M G F_{w}(-r b)}{(1-Z) M G F_{w}(-r b)+Z\left[e^{\left.-r\left(b-P_{e}\right) w_{g} L I M G F_{w}\left(-r P_{e}\right)+U I M G F_{w}(-r b)\right]}\right.}\right)
$$

$\operatorname{UIMGF}_{w}(-r b)$ is the upper incomplete moment generating function ${ }^{6}$ of order $(-r b)$. The risk premium depends on several parameters, including farmers' absolute risk aversion coefficient $(r)$, the marginal water value $(b)$, the exercise price $\left(P_{e}\right)$, the guaranteed water volume $\left(w_{g}\right)$, and the parameters of the gamma function that represents farmers' water availability ( $\alpha$ and $\lambda$ ). Changes in these parameters have quite a complex impact on the risk premium value. In Section 4, the application of the theoretical model to a real case will illustrate the relationship between the value of the risk premium and some of these parameters.

Equation (9) is best interpreted by inspecting the bracketed term within the logarithm. If the bracketed term is greater than 1 , then $R_{o p t_{a}}>0$. This holds if $e^{-r\left(b-P_{e}\right) w_{g}} L I M G F_{w}\left(-r P_{e}\right)<L I M G F_{w}(-r \mathrm{~b})$, which holds if $b>P_{e}$. The sense is that if the disutility of the left tail of the distribution covered by the option (for $w<w_{g}$ ) - which is captured by $\operatorname{LIMGF}\left(-r P_{e}\right)$ - is less than the disutility of the water supply risk (for $w<w_{g}$ ) without the option $\left(\operatorname{LIMGF}_{w}(-r \mathrm{~b})\right)$, then there will be a positive willingness to pay for the instrument $\left(R_{o p t_{a}}>0\right)$. However, if $b<P_{e}$, then $R_{o p t_{a}} \lesseqgtr 0$, because in this situation, while the cost of the purchased water is greater than its marginal productivity, it may or may not be compensated by the risk reduction effect of the contract.

Apart from this option contract, two other risk management tools are assessed in this paper for different exercise conditions: an option contract (b) with $\mathrm{Z}=1$; and a drought insurance policy. 


\subsubsection{Option contract $(b)$}

Option contract (b) allows the holder to exercise the option whenever his water allotment is below a pre-established guaranteed level $\left(w_{g}\right)$. The difference from option contract (a) is that there is no additional trigger $(Z=1)$ (additional condition for exercising the option) in this case. Thus, under option contract (b), option holders that pay the exercise price $\left(P_{e}\right)$ to sellers will, at the very least, have a water volume equivalent to $w_{g}$ every season.

The mathematical expression of the risk premium $\left(R_{o p t_{b}}\right)$ for this instrument is (see Appendix D)

$$
R_{\text {opt }_{b}}=\frac{1}{r} \ln \left(\frac{M G F_{w}(-r b)}{e^{-r\left(b-P_{e}\right) w_{g}} \operatorname{LIMGF_{w}(-rP_{e})+UIMGF_{w}(-rb)}}\right) .
$$

The risk premium for option contract (b) is greater than for option contract (a). Equation (10) is easier to interpret than Equation (5), because there is no risk associated with the execution of the contract. Therefore, $R_{o p t_{b}}>0$ holds if and only if $b>P_{e}$ and $L I M G F_{w}\left(-r P_{e}\right)<L I M G F_{w}(-r b)$, i.e., if the disutility of paying the premium is less than the disutility of not having the optioned water volume available.

While contract (b) is just a particular case of the contract (a), with $\mathrm{Z}=1$, it is more directly comparable to the insurance policy, because both guarantee some compensation (either in volume or in revenue) in the event of shortage. Also, the financial costs of contract (b) are easier to evaluate.

\subsubsection{Insurance}

The proposed insurance contract would have similar risk reduction effects as option contract (b). It offers a financial compensation for loss of profit if the water volume received by farmers is below the guaranteed volume $\left(w<w_{g}\right)$. 
Applying the same methodology as in the previous two cases, the risk premium is ${ }^{7}$ (see Appendix E):

$$
R_{\text {ins }}=\frac{1}{r} \ln \left(\frac{M G F_{w}(-r b)}{\gamma e^{-r b w g}+U I M G F_{w}(-r b)}\right),
$$

where $\gamma$ is the probability of farmers' water availability $(\widetilde{w})$ being less than $w_{g}$, i.e. the probability of receiving the insurance indemnity.

\subsection{Supply-side analysis of the instruments}

A distinction should be made between the risk premium $(R)$ and the premium actually paid by farmers. The risk premium represents farmers' willingness to pay for the use of a given available instrument. The premium actually paid is the amount of money that farmers pay sellers/insurance companies for access to the optioned water volume/indemnity if needed. Obviously, farmers will not pay a premium greater than their WTP for contracting the option/insurance.

The evaluation of the supply side of these instruments is just as important as analyzing farmers' WTP for different water supply management tools. The market price will determine the final decision to purchase one or other instrument. Each risk management tool (insurance and option contract) has its own pricing mechanism.

For an insurance policy, the basic premium is equivalent to the expected indemnity. Different costs (administrative costs, re-insurance costs, etc.) are added to this basic premium to calculate the final value of the premium that the farmer should pay to purchase the insurance policy. Thus, the commercial premium is

$$
P_{\text {ins }}=E\left[\max \left(b\left(w_{g}-\widetilde{w}\right), 0\right)\right] \times(1+C) .
$$


$P_{\text {ins }}$ is the commercial premium; $b\left(w_{g}-\widetilde{w}\right)$ is the expected compensation in a given year; and $C$ represents all the associated costs (expressed as a percentage of the pure premium).

The Black-Scholes-Merton model (Black and Scholes 1973; Merton 1973) is commonly used for option contracts. The model is defined as follows:

$$
P_{o p t}=S_{0} N\left(d_{1}\right)-X e^{-r T} N\left(d_{2}\right)
$$

with

$$
\begin{aligned}
& d_{1}=\frac{\ln \left(\frac{S_{0}}{X}\right)+\left(r+\frac{\sigma^{2}}{2}\right) T}{\sigma \sqrt{T}} \\
& d_{2}=d_{1}-\sigma \sqrt{T} .
\end{aligned}
$$

$P_{o p t}$ is the value of the option (contract premium); $S_{0}$ is the spot price for water; $N$ is the cumulative distribution function of a normal function; $X$ is the exercise price of the option $\left(P_{e}+P_{w}\right.$ in our case); $r$ is the interest rate (in $\left.\%\right) ; T$ is the time to maturity date in years; $\sigma$ is the volatility (in \%) of the underlying asset (water). The option contract premium plus the exercise price represents the total price of the option.

\section{Comparison between instruments}

In the following sections we compare the risk premium of option contracts (a) and (b) with the insurance policy.

\subsection{Comparison between option contract $(b)$ and insurance}

The risk premium for both cases $\left(R_{\text {opt }}\right.$ and $\left.R_{\text {ins }}\right)$ were stated in Section 2 (Equations (10) and (11)), and they differ only with regard to the denominator of the logarithm. In order to 
compare the risk premium value for these cases, we compare the value of their denominators. Insurance is preferred to option contract (b) $\left(R_{\text {ins }}>R_{\text {opt }}\right)$ if

$$
\begin{gathered}
e^{-r\left(b-P_{e}\right) w_{g}} L I M G F_{w}\left(-r P_{e}\right)+U I M G F_{w}(-r b)>\gamma e^{-r b w_{g}}+U I M G F_{w}(-r b) \\
\operatorname{LIMGF}_{w}\left(-r P_{e}\right)>\gamma e^{-r P_{e} w_{g}}
\end{gathered}
$$

Equation (16) compares the disutility of the risk associated with the left tail of the distribution $\left(w<w_{g}\right)$ of the option contract with the certainty equivalent of the tail guaranteed by the insurance. From further algebra with (16) we can conclude that if $P_{e}<0, R_{\text {ins }}$ will always be greater than $R_{o p t_{b}}$, and thus the insurance will be preferred to option contract (b).

$$
\begin{gathered}
e^{r P_{e} w_{g}} \operatorname{LIMGF_{w}}\left(-r P_{e}\right)-\gamma>0 \\
e^{r P_{e} w_{g}} \int_{0}^{w_{g}} e^{-r P_{e} w} f(w) d w-\int_{0}^{w_{g}} f(w) d w>0 \\
\int_{0}^{w_{g}}\left(e^{-r P_{e}\left(w-w_{g}\right)}-1\right) f(w) d w>0
\end{gathered}
$$

As the upper limit of the integral is $w_{g}, w$ will always be smaller than $w_{g}$. Thus, $e^{-r P_{e}\left(w-w_{g}\right)}>1$; and this expression would be positive for $P_{e}>0$.

Both instruments offer a similar protection level for farmers. However, in the case of the option contract, farmers must also pay an exercise price for getting the optioned volume. That is why the insurance risk premium is higher when the exercise price of the option contract is positive. The farmer would have to pay all the costs of the insurance (the insurance premium) at the beginning of the year. In the case of the option contract, the interaction between buyer and seller is a two-step process. First, all the contract terms are established: the premium, the exercise price and the optioned volume. Water availability is 
uncertain at this point, but the farmer has to decide whether to sign the option contract and pay the premium to the seller. In the second period, when the uncertainty disappears, the buyer has to decide whether to exercise the option, paying the exercise price for the optioned volume (Tomkins and Weber 2010).

If the price of the water acquired through the option contract were lower than the usual source of water $\left(P_{e}<0\right)$, then the option contract might be preferred to the insurance policy ${ }^{8}$.The reason of including this scenario in our analysis is that this situation has happened during the 2006-2008 drought period in Spain, when some water tariff exemptions were applied to farmers (see Garrido et al. 2012b and Section 5 of this paper).

The decision to purchase one instrument or the other would depend on the effect that each tool has on farmers' welfare. If $P_{o p t_{b}}$ and $P_{\text {ins }}$ are the premiums paid by farmers for each instrument, they will purchase the instrument that provides greater welfare; i.e. the difference between the risk premium and the premium paid is greater ${ }^{9}$. If $R_{o p t_{b}}-P_{o p t_{b}}>$ $R_{\text {ins }}-P_{\text {ins }}$, the farmer would purchase the option contract.

$$
\begin{gathered}
R_{o p t_{b}}=\frac{1}{r} \ln \left(\frac{N}{D_{\text {opt }}}\right) \text { and } R_{\text {ins }}=\frac{1}{r} \ln \left(\frac{N}{D_{\text {ins }}}\right) \\
R_{\text {opt }_{b}}-P_{o p t_{b}}>R_{\text {ins }}-P_{\text {ins }} \\
\\
P_{\text {opt }_{b}}-P_{\text {ins }}<\frac{1}{r} \ln \left(\frac{D_{\text {ins }}}{D_{\text {opt }}}\right)
\end{gathered}
$$

where $N$ is the numerator of the risk premium (which is the same for both the option contract (b) and the insurance); $D_{\text {opt }_{b}}$ is the denominator of the option contract's risk premium (see Eq. 10); and $D_{i n s}$ is the denominator of the risk premium of the insurance (see Eq. 11). 
Therefore, if $P_{o p t_{b}}<P_{\text {ins }}+\frac{1}{r} \ln \left(\frac{D_{\text {ins }}}{D_{\text {opt }}}\right)$, the farmer would prefer the option contract. The value of the premium paid that makes the farmer indifferent between both alternatives is $P_{\text {opt }}=P_{\text {ins }}+\frac{1}{r} \ln \left(\frac{D_{\text {ins }}}{D_{\text {opt }}}\right)$.

For a risk-averse farmer and $P_{e}>0, D_{\text {opt }}$ is greater than $D_{\text {ins }}$ (and $R_{\text {ins }}$ is greater than $\left.R_{\text {opt }_{b}}\right)$, and therefore $\frac{1}{r} \ln \left(\frac{D_{\text {ins }}}{D_{\text {opt }_{b}}}\right)<0$. Equation (18) would be

$$
P_{\text {ins }}-P_{\text {opt }_{b}}>-\frac{1}{r} \ln \left(\frac{D_{\text {ins }}}{D_{\text {opt }}}\right)>0
$$

This result implies that farmers will choose insurance even if they have to pay a higher premium than for an option contract, as long as the premium of the insurance does not surpass that of the option contract by more than $\frac{1}{r} \ln \left(\frac{D_{\text {ins }}}{D_{\text {opt }}}\right)$, which refers back to the discussion leading to equation 16 , above.

On the other hand, if $P_{e}<0$ (the optioned water is cheaper than the price the farmer pays for his regular water allotment), $D_{\text {ins }}$ is greater than $D_{o p t_{b}}$ (and $R_{o p t_{b}}$ is greater than $R_{\text {ins }}$ ), and therefore $\frac{1}{r} \ln \left(\frac{D_{\text {ins }}}{D_{\text {opt }}}\right)>0$. Equation (18) would then be

$$
P_{\text {opt }_{b}}-P_{\text {ins }}<\frac{1}{r} \ln \left(\frac{D_{\text {ins }}}{D_{\text {opt }}}\right)>0
$$

In this case, the farmer will purchase the option contract as long as this premium does not surpass the premium to be paid for insurance by more than $\frac{1}{r} \ln \left(\frac{D_{\text {ins }}}{D_{\text {opt }_{b}}}\right)$. Below, we discuss why $P_{e}<0$ would probably hold in some contexts. 


\subsection{Comparison between option contract (a) and insurance}

Similarly, let us compare option contract (a) and insurance. The probability of receiving compensation through insurance is greater than the probability of getting the optioned volume through this option contract. For risk-averse growers, $R_{\text {ins }}>R_{o p t_{a}}$ always holds for $P_{e}>0$ (proof available on request). If $P_{e}<0$, for very low exercise prices only, the WTP for this option contract could be slightly greater than $R_{\text {ins }}$. As in the previous comparison, farmers will choose insurance even if $P_{\text {ins }}$ is greater than the premium to be paid for this option contract, as long as the former does not exceed the latter by more than $\frac{1}{r} \ln \left(\frac{D_{\text {ins }}}{D_{\text {opta }}}\right)$.

In sum, when comparing two of these risk management tools ( $i$ and $j$ ), the decision rule that determines which instrument a risk-averse farmer will purchase is

$$
\begin{aligned}
& P_{i}<P_{j}+\frac{1}{r} \ln \left(\frac{D_{j}}{D_{i}}\right) \rightarrow i \\
& P_{i}>P_{j}+\frac{1}{r} \ln \left(\frac{D_{j}}{D_{i}}\right) \rightarrow j .
\end{aligned}
$$

From all the possible pair-wise comparisons of the analyzed instruments ${ }^{10}$, we establish the preference ordering for risk-averse farmers. The term in the logarithm captures the comparison of utility gains of instruments $i$ and $j$. This is shown in Figure 1 .

\section{HERE FIGURE 1}

Clearly, the parameters of each instrument will influence farmers' WTP for a risk management tool, specifying which factors are more decisive in the design of this type of tools ${ }^{11}$. As expected, a higher level of guarantee $\left(w_{g}\right)$ will increase the WTP for all the instruments. Higher values of the gamma parameter $\alpha$ increase the value of the guaranteed volume (which would increase the risk premium), whereas higher values of $\lambda$ have the opposite effect. A low exercise price compared with the price normally paid for the water 
allotment or for alternative sources can alter farmers' preferences for the different risk management tools considered in this study.

\section{Application to an irrigation district in Spain}

Currently, water trading mechanisms help reduce the risk of Spanish farmers not having enough water to irrigate their crops. Insurance providing coverage against water shortages is still under development in Spain (Pérez-Blanco and Gómez 2012, 2013; Ruiz et al. manuscript).

The 1999 Spanish National Water Law provides for agreements between water users to (temporarily or permanently) exchange water rights subject to several conditions and restrictions (Garrido et al. 2012b). During drought periods, irrigators in less water-endowed areas resort to spot water markets to increase their water availability. However, it is very hard to find water sellers in these situations, and prices may be extremely high because sellers have a dominant position. Gómez-Ramos and Garrido (2004), Cubillo (2010) and GómezRamos (2013), among others, discuss the advantages of water option contracts over spot water markets for the Spanish case.

Regarding insurance, while Spain has one of the most developed crop insurance systems worldwide (Antón and Kimura 2011), insurance covering water shortages is not

presently offered. Yet, several studies show the potential of drought insurance for Spanish agriculture. Quiroga et al. (2011) highlight the importance of reliable drought information to help farmers avoid the negative impacts of droughts and develop effective hydrological risk insurance schemes. Pérez-Blanco and Gómez $(2012,2013)$ focus on the potential of drought insurance to reduce aquifer overexploitation during water scarcity periods. 
Average water productivity for irrigation in Spain varies across regions, ranging from 0.3 to $3.4 € / \mathrm{m}^{3}$ (Gil et al. 2009) because climatic and soil conditions and water supply costs differ enormously. Irrigators also have to pay very different water prices, even within the same basin (Garrido and Calatrava 2009). But, in general, the irrigation water price is rather low in Spain, merely covering operation and management costs and a small share of investment costs. This heterogeneity in water productivity and prices could lead to differences in farmers' preferences for different water supply risk management mechanisms, such as the ones proposed in this study. In addition, this heterogeneity favors water exchanges between users with different productivity levels, especially if they are in different basins.

The theoretical framework presented in the previous sections is applied to irrigators in the Campo de Cartagena irrigation district in the Segura Basin (Southeast Spain). This is the largest irrigation district in the basin, and one of the largest in the country with 41,065 hectares. Open-air intensive horticulture is the predominant land use, covering $59 \%$ of the district's total irrigable area. The rest of the area is dedicated to citrus trees $(30 \%)$, greenhouses (7\%) and other fruit crops (4\%).

Farmers in this irrigation district have to deal with highly variable and uncertain water supplies. Of its total annual water quota $\left(141 \mathrm{hm}^{3}\right), 122 \mathrm{hm}^{3}$ should come from the Tagus Basin through the Tagus-Segura inter-basin aqueduct; $4.2 \mathrm{hm}^{3}$ from the Segura Basin, 2.2 $\mathrm{hm}^{3}$ from a desalination plant and $13.2 \mathrm{hm}^{3}$ from a wastewater treatment plant ${ }^{12}$. However, the Tagus-Segura resources are dependent on the hydrologic cycles in the area of origin, the Upper Tagus Basin, and annual allotments rarely reach the $122 \mathrm{hm}^{3}$ quota.

Our initial database contains the annual water allotment data for this irrigation district (1979-2012). Some preliminary modifications were required before this database could be 
used. First, the first two years of the database were removed, because the Tagus-Segura aqueduct was not working at full capacity during those two years. Second, the water volumes that come from the desalination plant (since 2001), from the wastewater treatment plant (since 2008) and from the spot market (2007-2010) were removed as well. The reason for doing this is that those volumes were available for the irrigation district only in some years of the period under study. And third, the resulting water allotment data series for this irrigation district was detrended, because runoff in the upstream Tagus Basin has clearly declined in the last decades (Lorenzo-Lacruz et al. 2010). After these recalculations were made, the water volume that this irrigation district currently receives from the desalination plant $\left(2.2 \mathrm{hm}^{3}\right)$ and from the wastewater treatment plant $\left(13.2 \mathrm{hm}^{3}\right)$ were added to the annual water volume datum. Ultimately, we get a detrended data series of the annual water allotment of this irrigation district for the 1981-2012 period, taking into account all the available water sources to which irrigators in this district currently have access.

We then calculated the probability distribution function (PDF) of the annual water allotment for this irrigation district (a gamma distribution function was fitted to these data; $\mathrm{Chi}^{2}=1.375 ; \mathrm{p}$ value $\left.=0.927\right)^{13}$. From this PDF, we obtained another PDF representing the mean water allotment per hectare, which is the one used in our analysis (see Figure 2).

\subsection{Willingness to pay for the different instruments}

With the water availability $\operatorname{PDF}(\widetilde{w})$, we apply the theoretical framework to obtain the risk premium values for each instrument. By changing the value of different parameters affecting the risk premium, we derive some conclusions about the influence of these parameters on farmers' WTP for these risk management tools.

\section{HERE FIGURE 2}


The water supply risk faced by farmers is related to the coefficient of variation (CV) of their water availability. Farmers' risk of not having enough water for irrigating their crops increases with CV values. Figure 3 shows farmers' WTP (expressed in euros per ha) for the studied instruments under different water availability $\mathrm{CV}$ values. The WTP is equivalent to the risk premium for each instrument $\left(R_{i}\right)$ obtained in the theoretical models. The maximum WTP for the option contract (a) is $€ 123$ per ha, but the maximum WTP for insurance is close to $€ 142$ per ha. The WTP for insurance can vary by approximately $€ 140$ per ha for the considered CV range.

\section{HERE FIGURE 3}

Farmers' risk preference is another factor that will affect their WTP for a given instrument. Figure 4 shows farmers' WTP for these tools, taking into account different risk aversion levels. The values of the Arrow-Pratt absolute risk aversion coefficient have been obtained taking into account farmers' wealth in the area ${ }^{16}$, and the relative risk aversion values normally applied to the agricultural sector. For the case study area, farmers' absolute risk aversion ranks from 0.00046 to 0.00185 , the relative risk aversion being 5-20. These high values of relative risk aversion are explained by the definition of the farmers' profit function, which depends exclusively on their water availability (a very realistic assumption in the area of study where water is the limiting production factor and rainfed crop production is not profitable). Similar values can be found in the literature (Kandel and Stambaugh 1991; Gómez-Limón et al. 2003).

\section{HERE FIGURE 4}

For less risk-averse farmers, WTP for these instruments ranges from $€ 131$ to $€ 164$ per ha (Figure 4). For higher risk aversion levels, the differences among the WTP for these tools increase. As expected, farmers' WTP for these instruments increases with risk aversion, 
reaching €241 per ha for the insurance, €208 for option contract (b) and €195 for option contract (a) at the highest risk aversion level. The WTP for option contract (a) is lower than for (b) because option contract (a) does not offer complete protection as there is a probability of the option not being able to be exercised due to parameter Z (see Section 2.2.1).

\section{HERE FIGURE 5}

As expected, Figure 5 shows that the WTP for a risk management tool increases with the probability of receiving the compensation. Since $\gamma$ is the probability of farmers' water availability being less than $w_{g}$, a greater $\gamma$ leads to a higher guaranteed level. Note that WTP grows concavely with $\gamma$. The value of this kind of instruments depends on the supply reliability they deliver. For a risk aversion level of 0.001 , the WTP for insurance decreases from nearly $€ 650$ when the probability of exercising the option is $80 \%$ to $€ 27$ when this probability is only $10 \%$. For a less risk-averse farmer $(r=0.0005)$, the WTP for these instruments is lower than above for all tools.

\section{HERE FIGURE 6}

Figure 6 shows the impact of a change in the option's exercise price on the farmers' WTP for option contracts. Obviously, the WTP for signing an option contract decreases with its exercise price. For instance, the WTP for the option contract (b) decreases from $€ 222$ to $€ 168$ per ha for the considered exercise price range. When the price paid for the optioned water volume is lower than the price of the regular water allotment $\left(P_{e}<0\right)$, the preference ordering for these tools changes (see Figure 1). In this case, the farmer would be willing to pay a higher premium for the option contract (b) than for the insurance. The WTP for the option contract (a) might be slightly higher than the WTP for insurance when the exercise price is very low. 
The previous results have been obtained under the assumption of constant absolute risk aversion (CARA). However, farmers are usually less risk averse when their wealth increases, exhibiting decreasing absolute risk aversion (DARA). To check that our CARA assumption does not change farmers' preferences for the proposed risk management tools in our case study, we have compared the above results with those obtained assuming a DARA utility function instead. We have used Monte Carlo simulation to calculate the PDF of the farmers' utility function for the different cases assuming both CARA and DARA utility functions, because there is no analytical solution to Equation 5 with DARA preferences and an asymmetric $\widetilde{w}$. Results show that there is no difference in farmers' preference ordering for these instruments between CARA to DARA (proof available upon request).

\subsection{Option contract and drought insurance prices}

To calculate the price of the drought insurance for farmers in the Campo de Cartagena irrigation district we have used Equation (12). We calculate the expected compensation from the PDF of farmers' water availability in this district for different guarantee levels $\left(w_{g}\right)$. This is the pure or basic premium. All the costs to be added to the basic premium to obtain the final price of an insurance policy are clearly defined by the Spanish crop insurance system: $9.24 \%$ of the basic premium for administrative costs, $5 \%$ for legal reserves, $20.66 \%$ for commercial mark-up, and 5.60\% for reinsurance costs (Varela 2008).

Our results show that the final price of the proposed insurance would be from $70 € /$ ha to $377 € /$ ha for the considered range of guarantee levels (when $b=0.7 € / \mathrm{m}^{3}$, which is the marginal value of water in our case study) (Figure 7). This price would be very close to the farmers' WTP for the drought insurance policy.

\section{HERE FIGURE 7}


Figure 7 shows the tentative prices of a water option contract for two different exercise prices. The price of the option contract has been calculated applying the BlackScholes-Merton formula (Eq.13). The final price of the option is the sum of the option premium plus the exercise costs (exercise price for each purchased cubic meter), transaction costs (nearly $1 \%$ based on previous water trading experiences in the area) and a payment for compensating third-party effects (almost 5\%, as applied in the option contracts between the Metropolitan Water District of Southern California and several Sacramento irrigation districts, reported by Hansen et al. (2013)). Although the total cost of the option contract (premium + exercise costs) considering $P_{e}=-0.08 € / \mathrm{m}^{3}$ is lower than the option with an exercise price of $0.12 € / \mathrm{m}^{3}$ (Figure 7), the premium of the former would be higher. This is because an option contract with such a low exercise price would be more valuable for an irrigator.

Although we are considering two different option contracts ( $a$ and b), we calculate a single price for the option contract. We would expect option contract (b) to have a higher price than option contract (a) because the probability of the option being able to be exercised is greater with option contract (b). Some authors have argued that this formula tends to underestimate option prices (Fleming et al. 2013). Thus, the real prices of the proposed option contracts might be higher than reported here.

Although drought insurance would have a higher price than an option contract, the final decision would depend on the potential for increasing farmers' welfare. If the difference between the WTP for the insurance and its price is greater than the difference between the WTP for the option contract and its final price, the farmer would choose to contract the insurance policy. As shown in Figure 7, the difference between the WTP and the price of the insurance is considerably lower than for the option contract. However, as mentioned above, option contract prices are likely to be higher than those obtained here. 


\section{Discussion}

By applying the theoretical framework to an irrigation district in Spain we can rank the analyzed instruments in different situations. As the results show, the insurance policy is the most preferred instrument (in terms of WTP). In this case, the received compensation could be used to overcome the financial loss caused by the drought situation or to buy water from another water source, including desalinized water. This risk management tool has the advantage that farmers would gain in revenue stability by transferring the risk of water shortage to the insurance market. One disadvantage is that farm labor, and both the processing and input supply sectors, would suffer the indirect consequences of reduced agricultural activity resulting from water shortages. In a real setting, however, the cost of insurance might be greater than the cost of an option contract, as our results show, and thus, a farmer could choose the option contract rather than the insurance unless it is sufficiently subsidized.

If we focus only on WTP values, it is the insurance the tool that obtained the highest value in our case study, followed by the option contract (b). However, if the costs are also taken into account, the prevalence of the insurance over the option contract could be reversed. The final decision to purchase one or other instrument would be based on: (i) the premium actually paid for each instrument (as previously explained in Section 3); (ii) the specific design elements of the instrument (maturity date, process to get the indemnity/optioned water, transaction costs); (iii) farmers' trust of the other agent involved in the contract (the water seller in the case of the option contract, and the insurance company when they purchase an insurance policy); and (iv) the exercise price of the option. If it is considerably lower than the price that the farmer has to pay for his water allotment from the regular supply source $\left(P_{w}\right)$, the WTP for option contract could increase and be greater than the WTP for the insurance (see Figure 6). 
In these cases, farmers' preference ordering for these risk management tools change (see Figure 1). During the 2005-2008 drought period, the Spanish Government permitted inter-basin market exchanges to alleviate the conditions of the hardest hit river basins (Garrido et al. 2012b). This was materialized in an agreement between the Canal de Estremera irrigation district (Tagus Basin) and the Sindicato Central de Regantes del Acueducto Tajo-Segura (SCRATS) irrigators' association. The price paid by farmers in the Segura Basin was $0.18 € / \mathrm{m}^{3}$ (they were exempted from paying an additional $0.12 € / \mathrm{m}^{3}$, which was the Tagus-Segura aqueduct tariff). In fact, the marginal value of irrigation water in the Tagus Basin is lower than the average price paid by water users in the Segura Basin, so this water will possibly be cheaper than their usual sources of supply ${ }^{21}$. This was the result of a bilateral negotiation between farmers in the area of origin (Tagus Basin) and farmers in the recipient basin (Segura Basin), and was accepted by the Spanish Ministry of the Environment for three consecutive years. It was beneficial for both parties, but was contested by downstream users in the Tagus Basin (Garrido et al. 2012b). In October 2013, the Environment Ministry and the regional governments concerned signed a memorandum ${ }^{22}$ of understanding to reformulate the inter-basin management rules, increasing the Tagus Basin prerequisites for exchanges, without, however, ruling out the possibility of inter-basin market exchanges between parties. Considering the differences of water productivity across regions (Garrido et al. 2010), market exchanges would be likely to continue if permitted by the Environment Ministry again. The potential transaction costs (transfer fees, environmental costs, etc.) would determine the exercise price and whether or not an insurance policy would be more attractive than an option contract.

Based on the current development of agricultural and drought insurance (for rainfed crops only), we would expect the insurance premium to cost at most $20-30 \%$ more than our calculated risk premium for several reasons. First, there is a lot of experience and expertise in 
the agro-insurance sector in Spain, gathered over 35 years (Antón and Kimura 2011). Secondly, risk is widely dispersed across 26 lines of crop insurance and 15 lines of livestock insurance, covering almost all insurable risks. Thirdly, there are two independently executed projects looking at the implementation details of this type of insurance that suggest its feasibility (Pérez-Blanco and Gómez 2013; Ruiz et al. manuscript).

Despite this, our results show that the insurance premium would be higher than the total price of the option contract. In fact, many authors highlight the need to subsidize insurance premiums to make them affordable for farmers (Bielza et al. 2008; Garrido and Zilberman 2008; Pérez-Blanco and Gómez 2013) ${ }^{23}$. It is important to recall that the pricing method used in this work for option contracts could be underestimating the total cost of this instrument, on top of which we have not added any other commission or additional cost. This should be taken into account when analyzing the results derived from our research. The cost of the water option contract is calculated, using the Black-Scholes-Merton formula, from the values of the option contract's characteristics (strike price, option premium, maturity date, spot market price), whereas the drought insurance commercial premium is calculated from the expected compensation to be paid in case of drought (foregone farmer's profit). In our empirical application (in a particularly profitable irrigated area of South Spain), the large differences between the marginal value of water $\left(b=0.7 € / \mathrm{m}^{3}\right)$ and the water price in the market $\left(0.13-0.33 € / \mathrm{m}^{3}\right)$ would explain the large differences between the costs of the drought insurance and the cost of the water supply option contract. In areas where the difference between the water price and the water productivity is smaller, the differences in the cost of these instruments would also be smaller. The total price of the insurance if the marginal value of water were $0.33 € / \mathrm{m}^{3}$ is also included in Figure 7 to show that the insurance premium in this case would be closer to the total price of the option contract. 
Farmers' WTP for the different water supply risk management tools analyzed is consistent with others from previous studies in this Spanish region (Tobarra 2008; Rigby et al. 2010; Pérez-Blanco and Gómez 2012). These authors evaluate the farmers' willingness to pay for reducing uncertainty with different water supply guarantee levels. They are therefore not directly comparable, but they do give us an idea of farmers' interest in these instruments in the region under study. Tobarra (2008) assessed farmers' WTP for a reduction in their water supply uncertainty, guaranteeing the average water allotment every year. According to his results, farmers' mean WTP in the Segura Basin (where the Campo de Cartagena irrigation district is located) is $€ 112-163$ per hectare, but may reach considerably higher values in the most productive areas of the basin, as is the case of the irrigation district considered in our study. Rigby et al. (2010) claimed that farmers in this irrigation district are willing to pay a rather high premium to increase their water supply reliability. Their results show that the average WTP of farmers for an increase of $25 \%$ in the certainty of getting the average water supply is €330. Pérez-Blanco and Gómez (2012) calculated basic risk premium values for specific crops in this area, expressed as a percentage of the expected production value in a normal hydrological year. For citrus crops, the WTP for drought insurance is the highest in the district (3.66-9.13\% of the expected production), ranging from $€ 199$ to $€ 234$. It is important to note that our proposed instruments have different objectives, as they are meant to guarantee a minimum water volume in dry years.

Similar research has been conducted for other Spanish river basins, highlighting the importance of water supply risk management tools for Spanish agriculture. As an example, Mesa-Jurado et al. (2012) performed a contingent valuation to assess farmers' WTP for a guaranteed water supply under scarcity conditions in the Guadalbullon River Sub-Basin (Guadalquivir Basin, Spain). They calculated a mean WTP of $€ 42.5$ and $€ 80.6$ per ha to ensure two-thirds of the average water application on irrigated olive farms in five out of 10 
years or in nine out of 10 years, respectively. Note, however, that farming is less profitable in the Guadalquivir Basin than in the Segura Basin.

As Figure 7 shows, farmers' WTP for these instruments would generally be higher than their prices. Thus, a risk-averse farmer would be interested in purchasing these water supply risk management tools.

\section{Conclusions}

Water supply uncertainty is one of the main risks faced by irrigators. New and innovative risk management tools can help them manage this risk factor, guaranteeing a minimum water volume each season to cover at least their basic water needs or else a financial compensation. We have analyzed irrigators' preferences and willingness to pay for different water supply risk management tools, and the tentative prices of these instruments. In Spain, at least, work is being done to develop this kind of instruments from a supply-side perspective, and they may be offered commercially shortly.

Our results show that farmers' decisions to use a water option contract or a drought insurance policy depend on their risk aversion, the profit function, the risk premium for each instrument and the additional administrative costs and fees, and the instrument's trustworthiness.

Knowing farmers' WTP for different risk management instruments is helpful for understanding the potential demand for these tools and designing the best mechanism for a particular region or agent. The comparisons presented in this paper can be applied to more general contexts, using different parameters and providing the best option for farmers based on their risk preferences. We conclude that an options menu might be better suited to the irrigated agricultural sector, especially if it has to regularly contend with various uncertain water supply sources. 
The potential of this type of mechanisms for Spanish agriculture, and other farming regions similarly subject to water supply risks, is potentially high, as drought episodes in this country are a recurrent phenomenon and may grow in the future as a result of climate change. Differences in water productivity across different water users facilitate the arrangement of this type of contracts. Although this study addresses the case of a farmer as a water option holder or as an insured agent, this same mechanism can be used by local or regional governments to respectively increase city water supply reliability during drought periods or enhance environmental flows. Some legislative and management changes are needed in order to implement these risk management tools in Spain.

\section{Notes}

${ }^{1}$ A MGF of a random variable is a specification of its probability distribution, which is a convenient means of collecting together all the moments of a random variable into a single power series.

${ }^{2}$ Our assessment takes into account only the changes in farmers' expected utility caused by differences in water availability (due to an option contract or an insurance).

${ }^{3} b=c-P_{w} ; c$ is the marginal profit of water use and $P_{w}$ is the water tariff.

${ }^{4}$ This applies to farmers relying on inter-basin transfers, where, because of area-of-origin preferences, no volume is transferred unless minimum water volumes are stored in the region whence the transfer is derived. Any other condition can be established as a trigger for the option contract in its place.

${ }^{5}$ A farmer exercising the water supply option contract will pay $P_{w}$ plus $P_{e}$ for the optioned volume. $P_{e}$ is defined as a surcharge on top of the price paid for the normal source of water supply $\left(P_{w}\right)$. If the exercise price agreed in the option contract were lower than the price paid for the normal source of water supply, $P_{e}$ would then be negative. This is not a very common situation, but it can occur when the contract is established between water users who have very different water productivities. In order to simplify the presentation of this approach, unless otherwise stated, only positive $P_{e}$ values are considered in the analysis.An example of an inter-basin exchange with a lower exercise price than $P_{w}$ that took place in the Spanish water market is presented in Section 5. 
${ }^{6} \mathrm{MGF}_{\mathrm{w}}(-\mathrm{rb})=\mathrm{UIMGF}_{\mathrm{w}}(-\mathrm{rb})+\operatorname{LIMGF}_{\mathrm{w}}(-\mathrm{rb})$

UIMGF and the LIMGF are calculated in the same way, the only difference being the value of the integral limits (the expression of $\operatorname{UIMGF}_{\mathrm{w}}(-\mathrm{rb})$ is given in Appendix C).

$$
\operatorname{LIMGF}_{w}(-\mathrm{rb})=\operatorname{MGF}_{\mathrm{w}}(-\mathrm{rb})\left[-\mathrm{Q}\left(\alpha,(\lambda+\mathrm{rb}) \mathrm{w}_{\mathrm{g}}\right)+1\right]
$$

$Q($.$) is a regularized gamma function.$

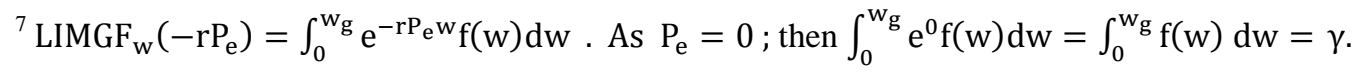

${ }^{8}$ Equation (17) can be rewritten as $\int_{0}^{w_{g}}\left(1-e^{-r P_{e}\left(w-w_{g}\right)}\right) f(w) d w<0$, where

$\int_{0}^{w_{g}}\left(1-e^{-r P_{e}\left(w-w_{g}\right)}\right) f(w) d w$ is the expected utility of $\left(-P_{e}\left(w-w_{g}\right)\right)$, i.e., the expected disutility of the increase in the cost of water due to obtaining it through the option contract instead of from the usual water source. If $P_{e}<0$, this expected utility would be positive and thus $R_{\text {ins }}<R_{\text {opt }_{b}}$.

${ }^{9}$ Obviously, irrigators will only sign the option contract if their WTP (risk premium, $R$ ) is greater than the price that they have to pay for the contract $(P) ; R>P$.

${ }^{10}$ See Appendix G, showing the remaining comparisons between the proposed tools.

11 A comparative statics analysis has been carried out in order to determine the influence of the main parameters on the value of the risk premium for each instrument. This material is available from the authors upon request.

\section{${ }^{12}$ http://www.crcc.es/informacion-general/informacion-c-r-c-c/}

${ }^{13}$ As the p-value approaches one, we have no basis to reject the hypothesis that the fitted distribution actually generated our data set (Source: @Risk Manual).

${ }^{14}$ The value of the gamma function's coefficients are: $\alpha=6.6292 ; \lambda=0.003146$.

${ }^{15}$ Parameter values for this figure are: absolute risk aversion $=0.0012$; marginal value of water, $\mathrm{b}=0.7 € / \mathrm{m}^{3}$; parameter affecting the probability of option (a) being exercised, $\mathrm{Z}=0.95$; guarantee level, $\mathrm{w}_{\mathrm{g}}=1406 \mathrm{~m}^{3}$ (probability $\gamma=0.2$ ); exercise price, $P_{e}=0.12 € / \mathrm{m}^{3}$. The chosen value for $b$ is the average marginal water value in the area according to Calatrava and Martínez-Granados (2012). 
${ }^{16}$ Wealth data sourced from the Spanish Farm Accountancy Data Network (RECAN), published by the Spanish Ministry of Agriculture, Food and Environment, http://www.magrama.gob.es/es/estadistica/temas/estadisticas-agrarias/economia/red-contable-recan/

${ }^{17}$ Parameter values for this figure are: marginal value of water, $b=0.7 € / \mathrm{m}^{3}$; parameter affecting the probability of exercise the option (a), Z=0.95; guarantee level, $\mathrm{w}_{\mathrm{g}}=1808 \mathrm{~m}^{3}$ (probability $\gamma=0.4$ ); exercise price, $P_{e}=0.12$ $€ / \mathrm{m}^{3}$.

${ }^{18}$ Parameter values for this figure are: marginal value of water, $b=0.7 € / \mathrm{m}^{3}$; parameter affecting the probability of exercise the option (a), $Z=0.95$; exercise price, $P_{e}=0.12 € / \mathrm{m}^{3}$.

${ }^{19}$ Parameter values for this figure are: absolute risk aversion level=0.0012; marginal value of water, $b=0.7$ $€ / \mathrm{m}^{3}$; parameter affecting the probability of exercise the option (a), $Z=0.95$; guarantee level, $\mathrm{w}_{\mathrm{g}}=1808 \mathrm{~m}^{3}$ (probability $\gamma=0.4$ )

${ }^{20}$ Parameter values for the WTP curves are: absolute risk aversion level $=0.001$; marginal value of water, $b=0.7$ $€ / \mathrm{m}^{3}$; parameter affecting the probability of exercise the option (a), $Z=0.95$.

${ }^{21} \mathrm{We}$ are aware of agreements between water users in the Tagus (sellers) and Segura basins (buyers) to sell water at a price of $0.06 € / \mathrm{m}^{3}$. If there is a drought period and they are exempted from paying the aqueduct tariff, the final price of this water would be lower than the usual water price.

\section{${ }^{22}$ http://www.scrats.es/wp-content/uploads/2013/10/131014-ENMIENDAS-ATS-_TEXTO-DEFINITIVO_.pdf}

\footnotetext{
${ }^{23}$ Nevertheless, in practice, the costs of insurance are usually very high, reaching levels sometimes unaffordable for potential customers. That is why agricultural insurance policies are subsidized in most countries. However, insuring water shortages based on clearly objective and transparent measures (such as those governing the Tagus-Segura Aqueduct and transfers) would perhaps be offered at reduced administrative costs, because there is no need to adjust losses in the fields. They could even be attached, as an optional guarantee, to already offered insurance policies covering crop losses. In this case, no matter whether the policy is subsidized, the administration and commercial cost of the premium may be reduced.
} 
Appendix A: Farmers' expected utility with no risk management tool

$$
\begin{aligned}
E U_{0}(\widetilde{\pi})=\int_{0}^{\bar{w}} U\left(\tilde{\pi}_{0}\right) f(w) d w=\int_{0}^{\bar{w}}\left[1-e^{-r(a+b w)}\right] f(w) d w=\int_{0}^{\bar{w}} f(w) d w-\int_{0}^{\bar{w}} e^{-r a} e^{-r b w} f(w) d w \\
=1-e^{-r a} \int_{0}^{\bar{w}} e^{-r b w} f(w) d w \\
=1-e^{-r a} M_{G F}(-r b)
\end{aligned}
$$

Appendix B: Expected utility and risk premium with option contract (a)

B.1)

$$
\begin{aligned}
& E U_{o p t_{a}}(\tilde{\pi})=Z \int_{0}^{w_{g}}\left[1-e^{-r\left(a+b w_{g}-P_{o p t}-P_{e}\left(w_{g}-w\right)\right)}\right] f(w) d w+ \\
& \left.(1-Z) \int_{0}^{w_{g}}\left[1-e^{-r\left(a+b w-P_{o p t}\right)}\right] f(w) d w+\int_{w_{g}}^{\bar{w}}\left[1-e^{-r\left(a+b w-P_{o p t}\right.} t_{a}\right)\right] f(w) d w= \\
& Z \gamma-Z e^{-r\left(a+b w_{g}-P_{o p t_{a}}-P_{e} w_{g}\right)} L I M G F_{w}\left(-r P_{e}\right)+\gamma-e^{-r\left(a-P_{o p t_{a}}\right)} L I M G F_{w}(-r b)-Z \gamma+ \\
& Z e^{-r\left(a-P_{o p t}\right)} L I M G F_{w}(-r b)+(1-\gamma)-e^{-r\left(a-P_{o p t}\right)} U I M G F_{w}(-r b)= \\
& 1-e^{-r\left(a-P_{o p t}\right)}\left(U I M G F_{w}(-r b)+\operatorname{LIMGF}_{w}(-r b)\right)-Z e^{-r\left(a+b w_{g}-P_{o p t_{a}}-P_{e} w_{g}\right)} L I M G F_{w}\left(-r P_{e}\right)+ \\
& Z e^{-r\left(a-P_{o p t}\right)} L_{I M G F_{w}}(-r b)=1-e^{-r\left(a-P_{o p t}\right)} M G F_{w}(-r b) \\
& -Z e^{-r\left(a+b w_{g}-P_{o p t_{a}}-P_{e} w_{g}\right)} L I M G F_{w}\left(-r P_{e}\right)+Z e^{-r\left(a-P_{o p t}\right)} L I M G F_{w}(-r b)
\end{aligned}
$$

B.2)

$$
E U_{0}(\tilde{\pi})=E U_{o p t_{a}}(\tilde{\pi})
$$

$1-e^{-r a} M G F_{w}(-r b)$

$$
\begin{aligned}
& =1-e^{-r\left(a-R_{o p t_{a}}\right)} M G F_{w}(-r b)-Z e^{-r\left(a+b w_{g}-R_{o p t_{a}}-P_{e} w_{g}\right)} L I M G F_{w}\left(-r P_{e}\right) \\
& +Z e^{-r\left(a-R_{o p t_{a}}\right)} L I M G F_{w}(-r b)
\end{aligned}
$$

$$
-e^{-r a} M G F_{w}(-r b)=-e^{-r a} e^{r R_{o p t}}\left[M G F_{w}(-r b)+Z e^{-r\left(b-P_{e}\right) w_{g}} L I M G F_{w}\left(-r P_{e}\right)\right]
$$




$$
R_{o p t_{a}}=\frac{1}{r} \ln \left(\frac{M G F_{W}(-r b)}{(1-Z) M G F_{W}(-r b)+Z\left[e^{-r(b-P e) w_{g}} \operatorname{LIMGF}_{W}\left(-r P_{e}\right)+U I M G F_{W}(-r b)\right]}\right)
$$

\section{Appendix C: Upper Incomplete Moment Generation Function (UIMGF)}

We consider that variable $\widetilde{w}$ follows a gamma distribution $f(w)$ :

$$
\begin{gathered}
f(w)=\frac{\lambda^{\alpha}}{\Gamma(\alpha)} w^{\alpha-1} e^{-\lambda w} \\
\operatorname{UIMGF}_{w}(-r b)=\int_{w_{g}}^{\bar{w}} e^{-r b w} \frac{\lambda^{\alpha}}{\Gamma(\alpha)} w^{\alpha-1} e^{-\lambda w} d w=\left[-\frac{\lambda^{\alpha} w^{\alpha} E_{1-\alpha}((\lambda+r b) w)}{\Gamma(\alpha)}\right]_{w_{g}}^{\bar{w}}
\end{gathered}
$$

$E$ is an exponential integral function.

$$
\begin{gathered}
E_{n}(z)=z^{n-1} \Gamma(1-n, z) \\
E_{1-\alpha}((\lambda+r b) w)=((\lambda+r b) w)^{-\alpha} \Gamma(\alpha,(\lambda+r b) w)
\end{gathered}
$$

So, the expression of $U I M G F_{w}(-r b)$ is

$$
\begin{array}{r}
U I M G F_{w}(-r b)=-\frac{\lambda^{\alpha}}{\Gamma(\alpha)}\left[w^{\alpha}(w(\lambda+r b))^{-\alpha} \Gamma(\alpha,(\lambda+r b) w)\right]_{w_{g}}^{\bar{w}}=-\frac{\lambda^{\alpha}}{\Gamma(\alpha)}\left[(\lambda+r b)^{-\alpha} \Gamma\left(\alpha,(\lambda+b r) w_{g}\right)\right]_{w_{g}}^{\bar{w}}= \\
\frac{\lambda^{\alpha}}{(\lambda+r b)^{\alpha}}\left[\frac{-\Gamma\left(\alpha,(\lambda+r b) w_{g}\right)}{\Gamma(\alpha)}\right]_{w_{g}}^{\bar{w}}=M G F_{w}(-r b)\left(\left[Q\left(\alpha,(\lambda+r b) w_{g}\right)\right]-[Q(\alpha,(\lambda+r b) \bar{w})]\right)(c .2)
\end{array}
$$

$Q($.$) is the regularized gamma function, whose domain is [0,1]$.

\section{Appendix D: Expected utility and risk premium with option contract (b)}

If we assume that irrigators will always exercise the option at the maturity date when their water allotment is below $w_{g}$, their profit function is

$$
\begin{gathered}
\tilde{\pi}_{o p t_{b}}(w)=a+b \widetilde{w}-P_{o p t_{b}} \quad \text { if } \widetilde{w} \geq w_{g} \\
\tilde{\pi}_{o p t_{b}}(w)=a+b \mathrm{w}_{g}-P_{o p t_{b}}-P_{e}\left(w_{g}-\widetilde{w}\right) \quad \text { if } \widetilde{w}<w_{g}
\end{gathered}
$$


D.1)

$$
\begin{gathered}
E U_{o p t_{b}}(\tilde{\pi})=\int_{0}^{w_{g}}\left[1-e^{-r\left(a+b w_{g}-P_{o p t_{b}}-P_{e}\left(w_{g}-w\right)\right)}\right] f(w) d w \\
+\int_{w_{g}}^{\bar{w}}\left[1-e^{-r\left(a+b w-P_{o p t_{b}}\right)}\right] f(w) d w=\gamma-e^{-r\left(a+b w_{g}-P_{o p t_{b}}-P_{e} w_{g}\right)} \int_{0}^{w_{g}} e^{-r P_{e} w} f(w) d w+(1-\gamma)- \\
e^{-r\left(a-P_{o p t_{b}}\right)} \int_{w_{g}}^{\bar{w}} e^{-r b w} f(w) d w= \\
1-e^{-r\left(a+b w_{g}-P_{o p t_{b}}-P_{e} w_{g}\right)} \operatorname{LIMGF}_{w}\left(-r P_{e}\right)-e^{-r\left(a-P_{o p t_{b}}\right)} \operatorname{UIMGF}_{w}(-r b)
\end{gathered}
$$

D.2)

$$
\begin{aligned}
& E U_{0}(\tilde{\pi})=E U_{o p t_{b}}(\tilde{\pi}) \\
& 1-e^{-r a} M G F_{w}(-r b)=1-e^{-r\left(a+b w_{g}-R_{o p t_{b}}-P_{e} w_{g}\right)} L I M G F_{w}\left(-r P_{e}\right)-e^{-r\left(a-R_{o p t_{b}}\right)} U I M G F_{w}(-r b) \\
& -e^{-r a} M G F_{w}(-r b)=-e^{-r\left(a+b w_{g}-R_{o p t_{b}}-P_{e} w_{g}\right)} \operatorname{LIMGF}_{w}\left(-r P_{e}\right)-e^{-r\left(a-R_{o p t_{b}}\right)} U I M G F_{w}(-r b) \\
& M G F_{w}(-r b)=e^{r R_{o p t}}\left[e^{-r\left(b-P_{e}\right) w_{g}} \operatorname{LIMGF_{w}}\left(-r P_{e}\right)+\operatorname{UIMGF}_{w}(-r b)\right] \\
& R_{o p t_{b}}=\frac{1}{r} \ln \left(\frac{M G F_{W}(-r b)}{e^{-r(b-P e) w g} \operatorname{LIMGF}_{W}\left(-r P_{e}\right)+U I M G F_{W}(-r b)}\right)
\end{aligned}
$$

\section{Appendix E: Expected utility and risk premium with insurance}

The farmers' profit function in this case is

$$
\begin{aligned}
& \tilde{\pi}_{i n s}(w)=a+b \widetilde{w}-P_{\text {ins }} \quad \text { if } \widetilde{w} \geq w_{g} \\
& \tilde{\pi}_{i n s}(w)=a+b \mathrm{w}_{g}-P_{\text {ins }} \text { if } \widetilde{w}<w_{g}
\end{aligned}
$$

E.1)

$$
E U_{i n s}(\tilde{\pi})=\int_{0}^{w_{g}} 1-e^{-r\left(a+b w_{g}-P_{i n s}\right)} f(w) d w+
$$




$$
\begin{gathered}
\int_{w_{g}}^{\bar{w}} 1-e^{-r\left(a+b w-P_{i n s}\right)} f(w) d w=\gamma-\gamma e^{-r\left(a+b w_{g}-P_{\text {ins }}\right)}+(1-\gamma)-e^{-r\left(a-P_{\text {ins }}\right)} U I M G F_{w}(-r b)=1- \\
\gamma e^{-r\left(a+b w_{g}-P_{\text {ins }}\right)}-e^{-r\left(a-P_{\text {ins }}\right)} U I M G F_{w}(-r b)
\end{gathered}
$$

E.2)

$$
\begin{gathered}
E U_{0}(\tilde{\pi})=E U_{\text {ins }}(\tilde{\pi}) \\
1-e^{-r a} M G F_{w}(-r b)=1-\gamma e^{-r\left(a+b w_{g}-R_{\text {ins }}\right)}-e^{-r\left(a-R_{\text {ins }}\right)} U I M G F_{w}(-r b) \\
R_{\text {ins }}=\frac{1}{r} \ln \left(\frac{M G F_{w}(-r b)}{\gamma e^{-r b w g}+U I M G F_{w}(-r b)}\right)
\end{gathered}
$$

\section{Appendix F: Comparison of instruments}

\section{Comparison between the two option contracts (a) and (b)}

We first compare the risk premiums and then assess the conditions that make one instrument more attractive to the farmer than the other. $R_{o p t_{b}}$ will be greater than $R_{o p t_{a}}$ for all cases. Intuitively, the conclusion is the same, as option contract (b) offers more guarantees than contract (a), and the probability of the farmer being able to purchase the optioned volume at the maturity date is greater.

If $R_{o p t_{b}}>R_{o p t_{a}}$, then

$$
\begin{gathered}
e^{-r\left(b-P_{e}\right) w_{g}} L I M G F_{w}\left(-r P_{e}\right)+U I M G F_{w}(-r b) \\
<(1-Z) M G F_{w}(-r b)+\mathrm{Z}\left[e^{-r\left(b-P_{e}\right) w_{g}} L I M G F_{w}\left(-r P_{e}\right)+U I M G F_{w}(-r b)\right] \\
e^{-r\left(b-P_{e}\right) w_{g}} \operatorname{LIMGF}_{w}\left(-r P_{e}\right)+\operatorname{UIMGF}_{w}(-r b)<M G F_{w}(-r b)
\end{gathered}
$$

For $R_{\text {opt }_{b}}$ to be positive, the above expression must hold (as the numerator of the logarithm on the right side of the expression has to be greater than the denominator on the left side).

We calculate the conditions that determine whether farmers will take out an option contract or insurance thus:

$$
P_{o p t_{b}}-P_{o p t_{a}}<\frac{1}{r} \ln \left(\frac{D_{o p t_{a}}}{D_{o p t_{b}}}\right)
$$


If $P_{o p t_{b}}<P_{o p t_{a}}+\frac{1}{r} \ln \left(\frac{D_{o p t_{a}}}{D_{o p t_{b}}}\right)$, they would choose the option contract (b); and if $P_{o p t_{b}}>P_{o p t_{a}}+$ $\frac{1}{r} \ln \left(\frac{D_{o p t_{a}}}{D_{o p t_{b}}}\right)$, they would purchase the option contract (a) $\left(D_{o p t_{a}}\right.$ is always higher than $\left.D_{o p t_{b}}\right)$. The farmer would be indifferent to the two if $P_{o p t_{b}}=P_{o p t_{a}}+\frac{1}{r} \ln \left(\frac{D_{o p t_{a}}}{D_{o p t_{b}}}\right)$.

\section{References}

Antón J, Kimura S (2011) Risk Management in Agriculture in Spain. OECD Food, Agriculture and Fisheries Papers No. 43, OECD Publishing. http://dx.doi.org/10.1787/5kgj0d57w0wd-en. Cited 15 Sept 2013.

Bielza M, Conte C, Dittmann C, Gallego J, Stroblmair J (2008) Agricultural Insurance Schemes. Directorate General, JRC. European Commission.

Bjornlund H (2006) Can water assist irrigators Managing Increased Supply Risk? Some Australian experiences. Water Int 31(2): 221-232.

Black F and Scholes MS (1973) The pricing of options and corporate liabilities. J Polit Econ 81:637-654.

Brown C, Carriquiry M (2007) Managing hydroclimatological risk to water supply with option contracts and reservoir index insurance. Water Resour Res 43, W11423.

Calatrava J, Garrido A (2005a) Spot water markets and risk in water supply. Agr Econ 33: 131-143.

Calatrava J, Garrido A (2005b) Modelling water markets under uncertain water supply. Eur Rev Agric Econ 32(2): 119-142. 
Calatrava J, Martínez-Granados D (2012) El valor del agua en el regadío de la cuenca del Segura y en las zonas regables del trasvase Tajo-Segura. Economía Agraria y Recursos Naturales 12(1): 5-31.

Cerdá E and Quiroga S (2008) Cost-Loss Decision Models with Risk Aversion. ICEI Working Papers, WP 01/08.

Cheng W-Ch, Hsu N-S, Cheng W-M, Yeh W-G (2011) Optimization of European Call Options considering physical delivery network and reservoir operation rules. Water Resour Res 47, W10501.

Collender RN, Zilberman D (1985) Land Allocation under Uncertainty for Alternative Specifications of Return Distributions. Am J Agric Econ 67 (4): 779-786.

Cubillo F (2010) Looking for efficiency through integrated water management between agriculture and urban uses. Water Science and Technology: Water Supply 10(4): 584-590.

Cui J, Schreider S (2009) Modelling of pricing and market impacts for water options. J Hydrol 371: 31-41.

Cummins T, Thompson C (2002) Anticipating the Next Level of Sophistication in Water Markets. Connections 4:4-9.

FAO (2003) Unlocking the Water Potential of Agriculture. Natural Resources Management and Environment Department, FAO. Rome, Italy.

Fleming E, Villano R, Williamson B (2013) Structuring Exotic Options Contracts on Water to Improve the Efficiency of Resource Allocation in the Australian Water Market. Australasian Agribusiness Perspectives, paper 96. 
Garrido A (2007) Water markets design and evidence from experimental economics. Environ Resour Econ 38: 311-330.

Garrido A, Zilberman D (2008) Revisiting the demand of agricultural insurance: the case of Spain. Agric Finance Rev 68: 43-66.

Garrido A, Calatrava J (2009) Agricultural Water Pricing: EU and Mexico, OECD, Paris.

Garrido A, Gómez-Ramos A (2009) Propuesta para la implementación de un centro de intercambio basado en contratos de opción. In: Gómez-Limón JA, Calatrava J, Garrido A, Sáez FJ and Xabadia A (eds) La economía del agua de riego en España. Fundación Cajamar, pp. 321-341.

Garrido A, Llamas MR, Varela-Ortega C, Novo P, Rodríguez-Casado R, Aldaya MM (2010) Water Footprint and Virtual Water Trade in Spain. Springer. New York.

Garrido A, Bielza M, Rey D, Mínguez MI, Ruiz-Ramos M (2012a) Insurance as an Adaptation to Climate Variability in Agriculture. In: Mendelsohn R and Dinar A (eds) Handbook on Climate Change and Agriculture. Edward Elgar, pp.420-445.

Garrido A, Rey D, Calatrava J (2012b) Water trading in Spain. In: de Stefano L. and Llamas MR (eds) Water, Agriculture and the Environment in Spain: can we square the circle? CRC Press, Botín Foundation, pp. 205-216.

Gil M, Garrido A, Gómez-Ramos A (2009) Análisis de la productividad de la tierra y del agua en el regadío español. In: Gómez-Limón JA, Calatrava J, Garrido A, Sáez FJ, Xabadia A (eds) La economía del agua de riego en España. Fundación Cajamar, pp. 95-114.

Gómez-Limón JA, Riesgo L, Arriaza M (2002) Agricultural Risk Aversion Revisited: A Multicriteria Decision-Making Approach. Paper prepared for presentation at the Xth 
EAAE Congress 'Exploring Diversity in the European Agri -Food System', Zaragoza (Spain), 28-31 August 2002.

Gómez-Limón JA, Arriaza M, Riesgo L (2003) An MCDM analysis of agricultural risk aversion. Eur J Oper Res 151: 569-585.

Gómez-Ramos A, Garrido A (2004) Formal risk-transfer mechanisms for allocating uncertain water resources: The case of option contracts. Water Resour Res 40, W12302.

Gómez-Ramos A (2013) Drought management, uncertainty and option contracts. In: Maestu J (ed) Water Trading and Global Water Scarcity: International Experiences. RFF Press, pp. 286-297.

Hansen K, Howitt R, Williams J (2006) Implementing Option Markets in California To Manage Water Supply Uncertainty. Paper presented at the American Agricultural Economics Association Annual Meeting, Long Beach, California July 23-36.

Hansen K, Howitt R, Williams J (2013) Water trades in the western United States. In: Maestu J (ed) Water Trading and Global Water Scarcity: International Experiences. RFF Press, pp. 56-67.

Hardaker JB (2000) Some issues in dealing with risk in agriculture. Working Papers in Agricultural and Resources Economics. Armidale, N.S.W. School of Economic Studies. University of New England.

Hardaker JB, Huirne RBM, Anderson JR, Lien G (2004) Coping with risk in agriculture. Second edition, CABI publishing.

Just DR, Peterson H (2010) Is Expected Utility Theory Applicable? A Revealed Preference Test. Am J Agric Econ 92(1): 16-27. 
Kahneman D, Tversky A (1979) Prospect theory: an analysis of decision under risk. Econometrica 47: 263-291.

Kandel S, Stambaugh RF (1991) Asset returns and inter-temporal preferences. Journal of Monetary Econ 27 (1): 39-71.

Lefebvre M (2011) Irrigation water allocation mechanisms and drought risk management in agriculture. Doctoral Thesis, University of Montpellier I.

Leiva AJ, Skees J (2008) Using Irrigation Insurance to Improve Water Usage of the Rio Mayo Irrigation System in Northwestern Mexico. World Development 36(12): 2663-2678.

Lorenzo-Lacruz J, Vicente-Serrano SM, López-Moreno JI, Beguería S, García-Ruiz JM, Cuadrat JM (2010) The impact of droughts and water management on various hydrological systems in the headwaters of the Tagus River (central Spain). J Hydrol 386:13-26.

Merton RC (1973) Theory of rational option pricing. Bell J Econ Manage Science 4:141-183.

Mesa-Jurado MA, Martín-Ortega J, Ruto E, Berbel J (2012) The economic value of guaranteed water supply for irrigation under scarcity conditions. Agr Water Manage $113: 10-18$

Mongin P (1997) Expected Utility Theory. In: Davis J., Hands W. and Maki U (eds) Handbook of Economic Methodology. Edward Elgar, London, pp 342-350.

OECD (2009). Managing risk in agriculture: a holistic approach. OECD publishing.

Pérez-Blanco CD, Gómez CM (2012) Design of optimum private insurance schemes as a means to reduce water overexploitation during drought events. A case study in Campo de Cartagena (Segura River Basin, Spain).Paper presented at 86th Annual 
Conference of the Agricultural Economics Society, University of Warwick, United Kingdom, April.

Pérez-Blanco CD, Gómez CM (2013) Designing optimum insurance schemes to reduce water overexploitation during drought events: a case study of La Campiña, Guadalquivir River Basin, Spain. J of Environ Econ and Policy 2(1): 1-15.

Quiroga S, Garrote L, Fernandez-Haddad Z, Iglesias A (2011) Valuing drought information for irrigation farmers: potential development of a hydrological risk insurance in Spain. Spanish J Agric Res 9(4): 1059-1075.

Rigby D, Alcon F, Burton M (2010) Supply uncertainty and the economic value of irrigation water. Eur Rev Agric Econ 37(1): 97-117.

Ruiz J, Bielza M., Garrido A, Iglesias A (2014) Managing drought economic effects through insurance schemes based on local water availability. Manuscript.

Sivakumar MVK, Motha RP (2007) Managing Weather and Climate Risks in Agriculture, Springer.

Tobarra MA (2008) Gestión del recurso natural agua en situaciones de información asimétrica, racionamiento e incertidumbre. Doctoral Thesis, Universidad Politécnica de Cartagena, Murcia, Spain

Tomkins CD, Weber TA (2010) Option contracting in the California Water Market. J Regul Econ 37: 107-141.

Varela D (2008) Recargos de las primas: funciones y criterios de cálculo. Presented at the Course "Marketing del seguro Aspectos técnicos del cálculo de las primas de seguros agro-pecuarios”. Madrid, CEIGRAM, 18-19th November 2008. 
Williamson B, Villano R, Fleming E (2008) Structuring Exotic Option Contracts on Water to Improve the Efficiency of Resource Allocation in the Water Spot Water. Paper presented at AARES 52nd Annual Conference, February 2008.

Zeuli KA, Skees JR (2005)Rainfall Insurance: A Promising Tool for Drought Management. Water Res Development 21 (4): 663-675.

\section{Figures}

Figure 1. Farmers' willingness to pay for risk management tools (according to the resulting risk premium for each case)

Figure 2. Probability density function of farmers' water availability $\left(\mathrm{m}^{3}\right)$ per hectare in the Campo de Cartagena irrigation district ${ }^{14}$

Figure 3. Farmers' willingness to pay for each instrument by water availability coefficient of variation values ${ }^{15}$

Figure 4. Farmers' willingness to pay for these instruments by different risk aversion levels ${ }^{17}$

Figure 5. Farmers' willingness to pay (€/ha) for each instrument by different probabilities of exercising the option/receiving the indemnity $(\gamma)^{18}$. Absolute risk aversion level $=0.0005$ and 0.001

Figure 6. Farmers' willingness to pay for each instrument by different exercise prices ${ }^{19}$

Figure 7. Prices $(€ /$ ha) for option contracts and drought insurance, and WTP for these instruments for different guarantee levels ${ }^{20}\left(\mathrm{w}_{\mathrm{g}}\right)$ 

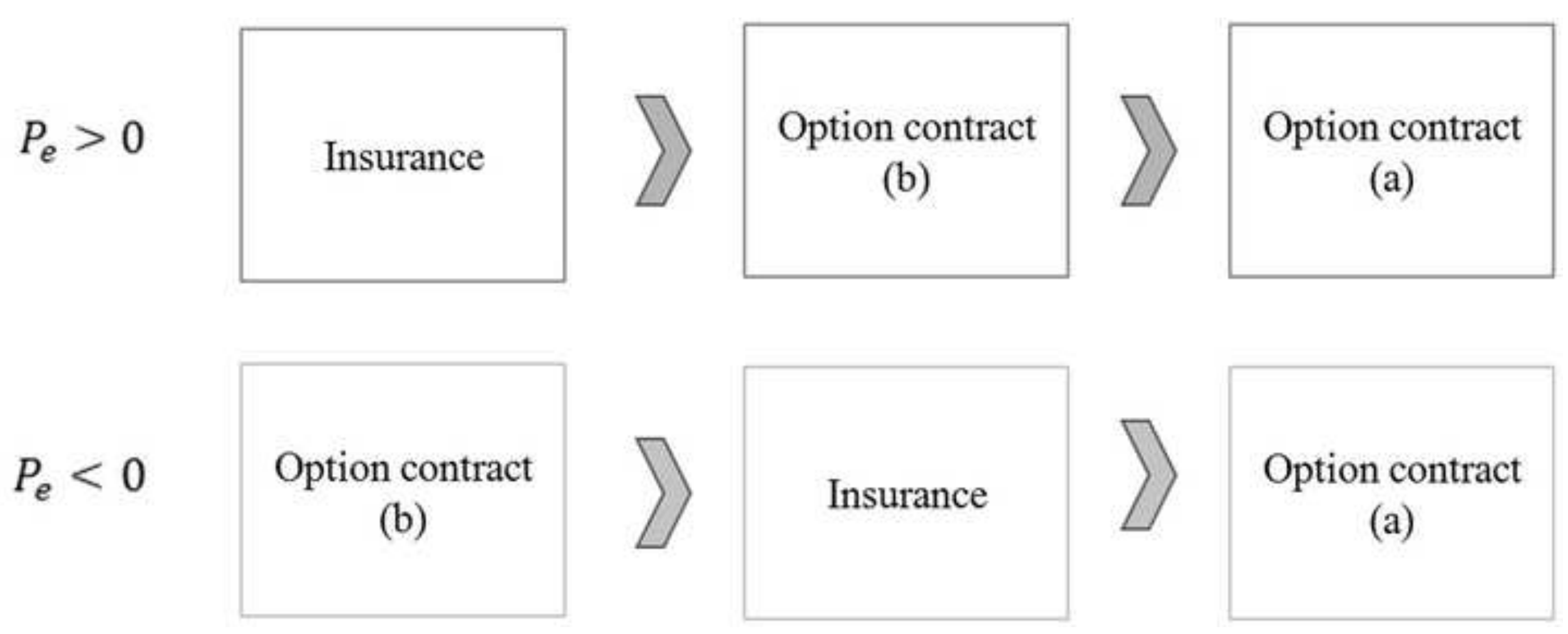


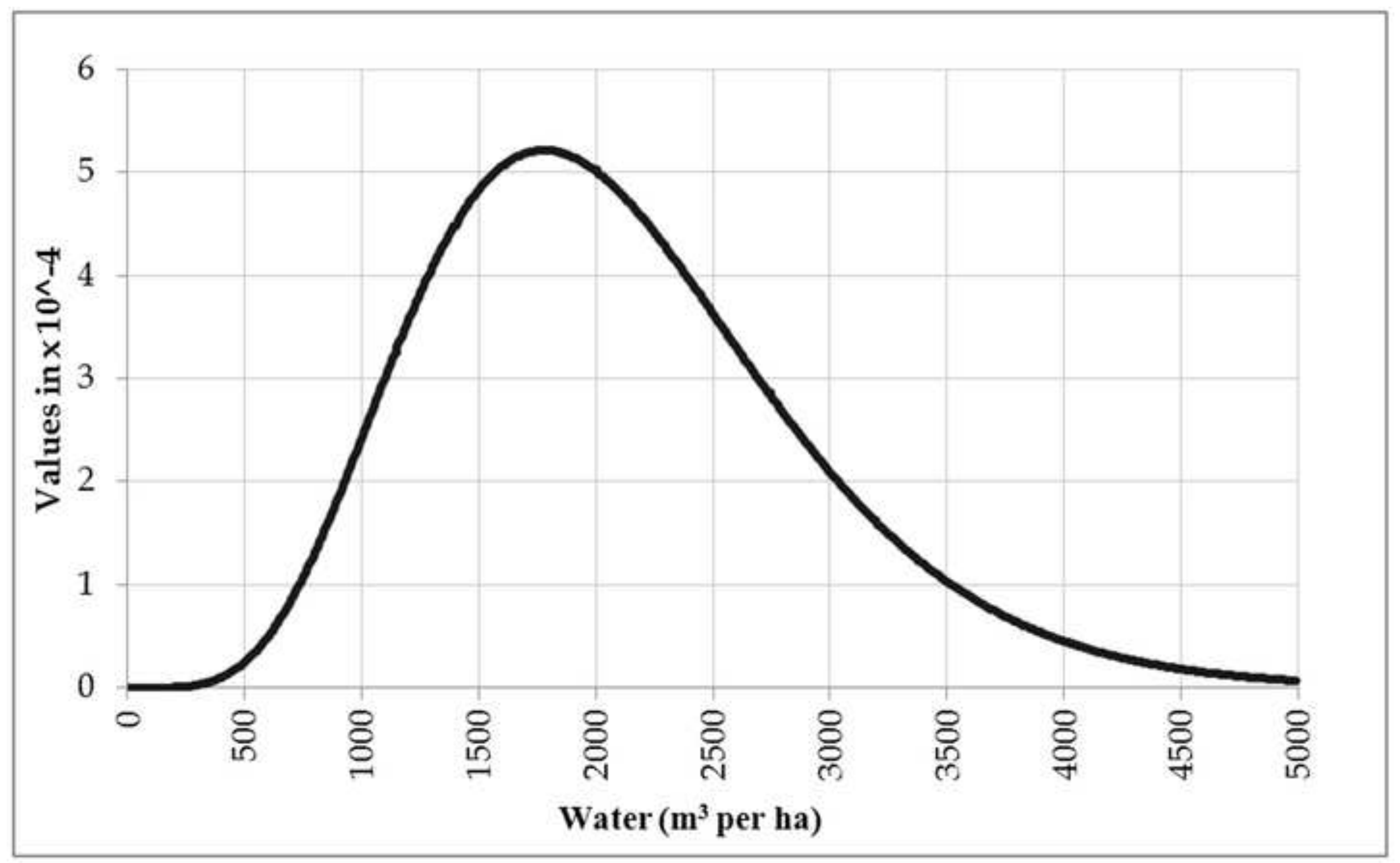




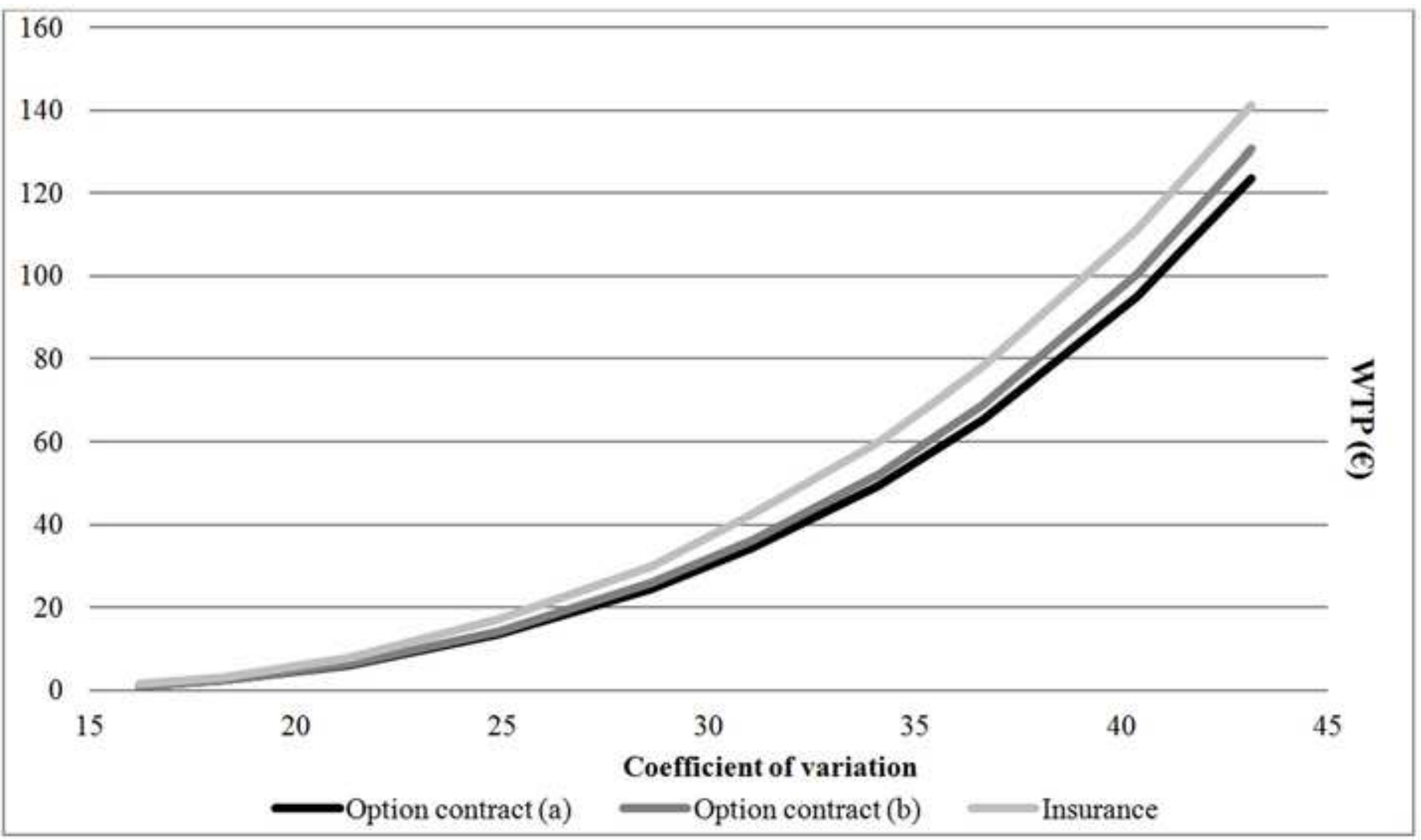




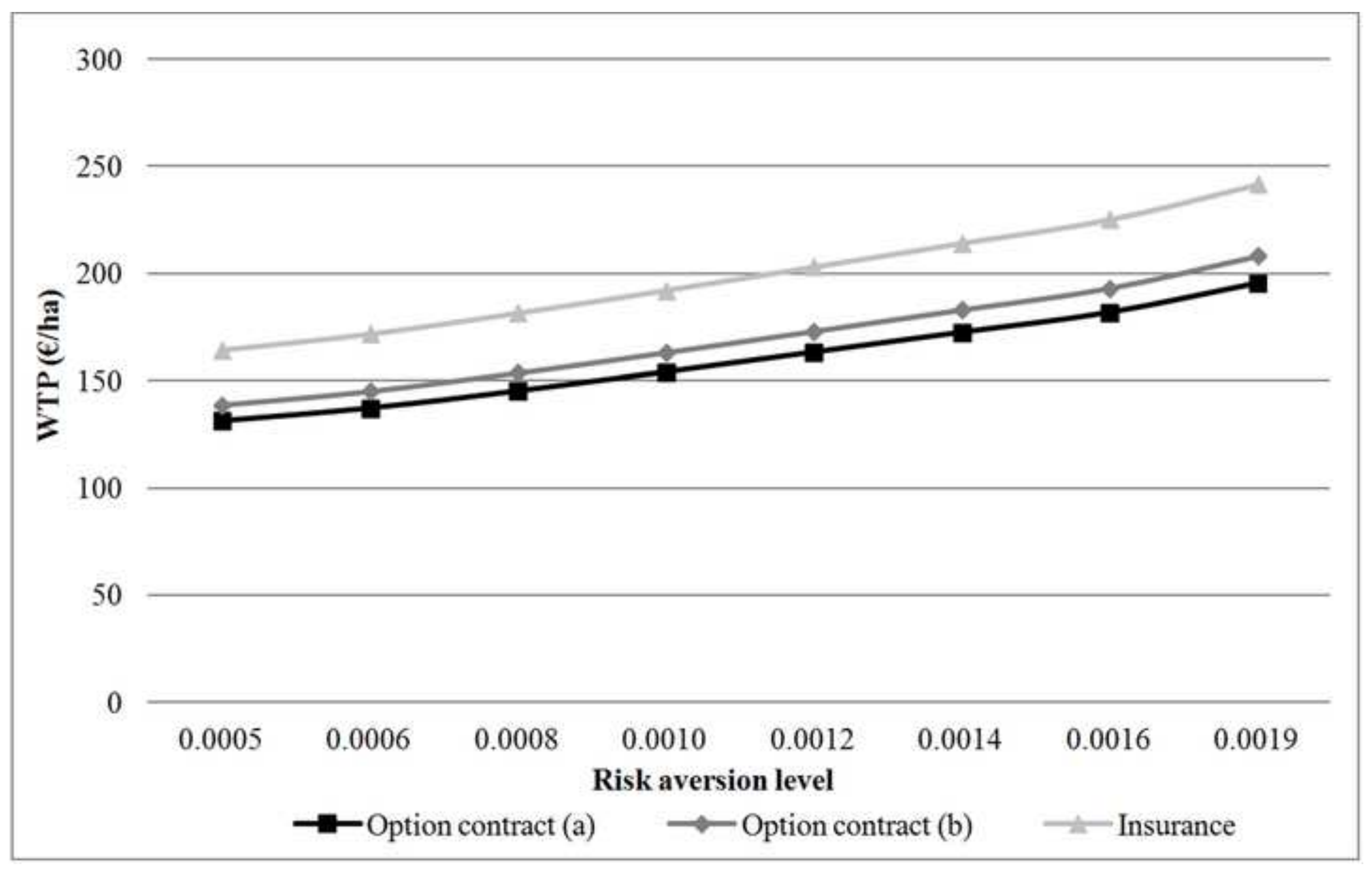




$$
r=0.0005
$$

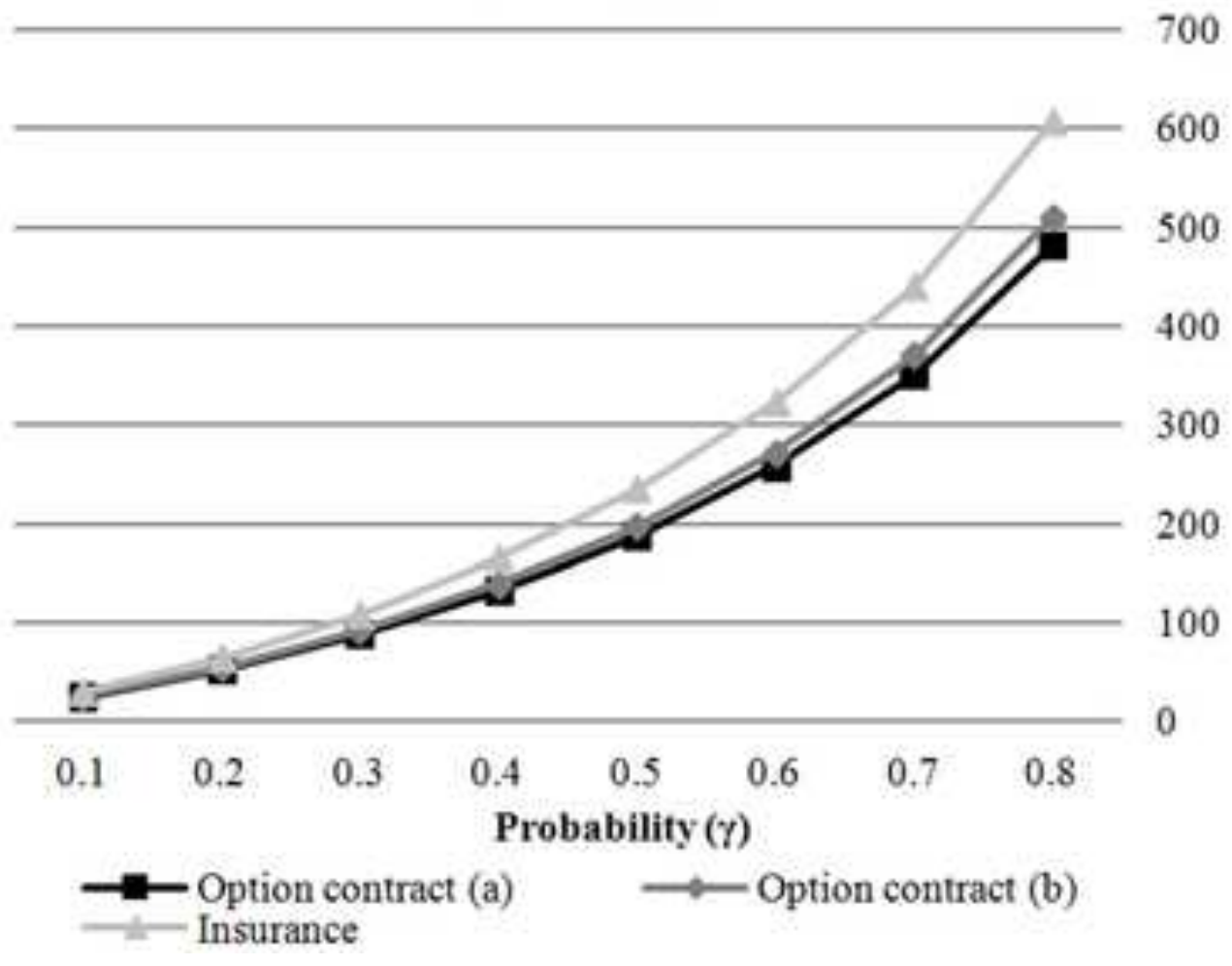

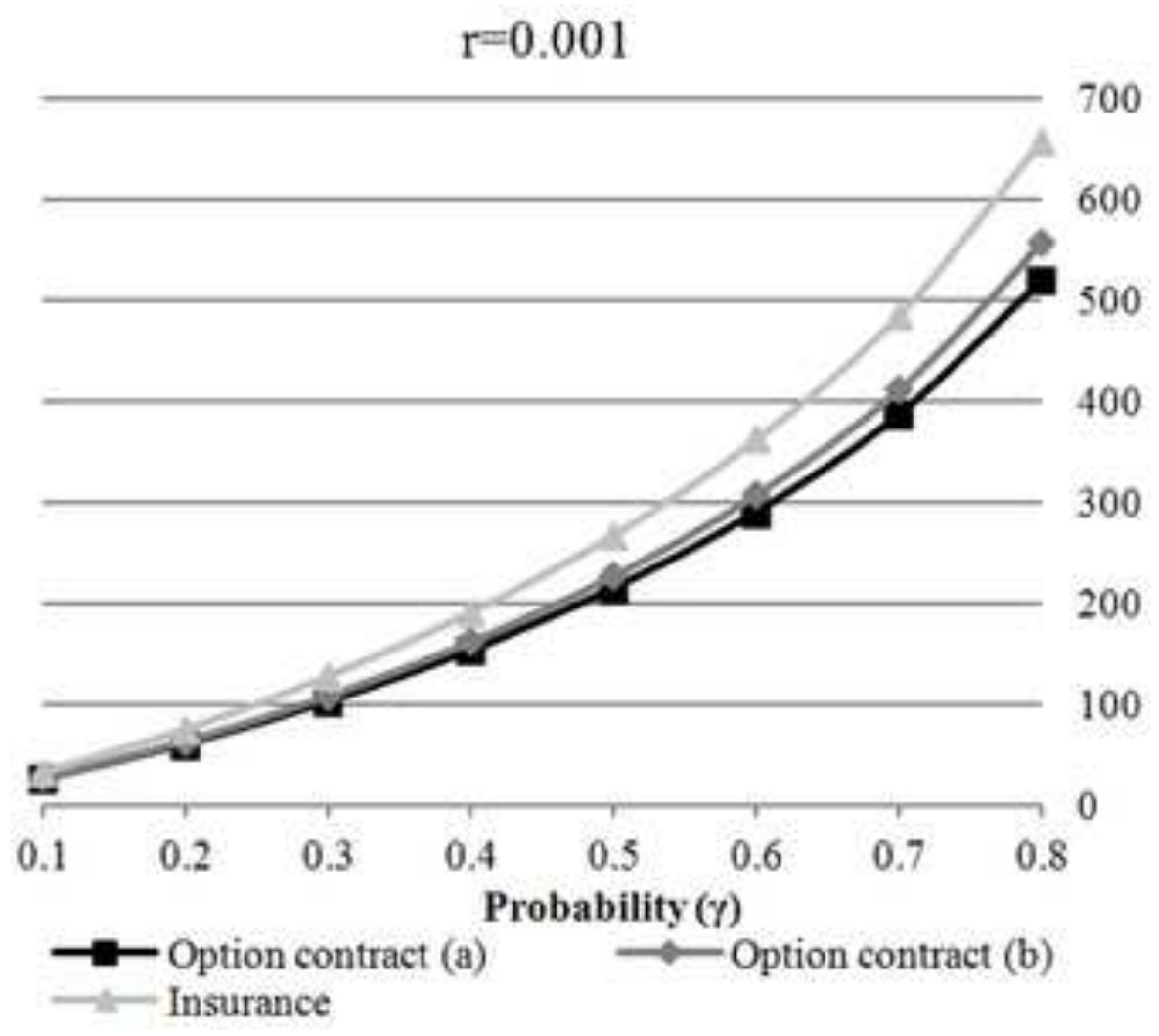




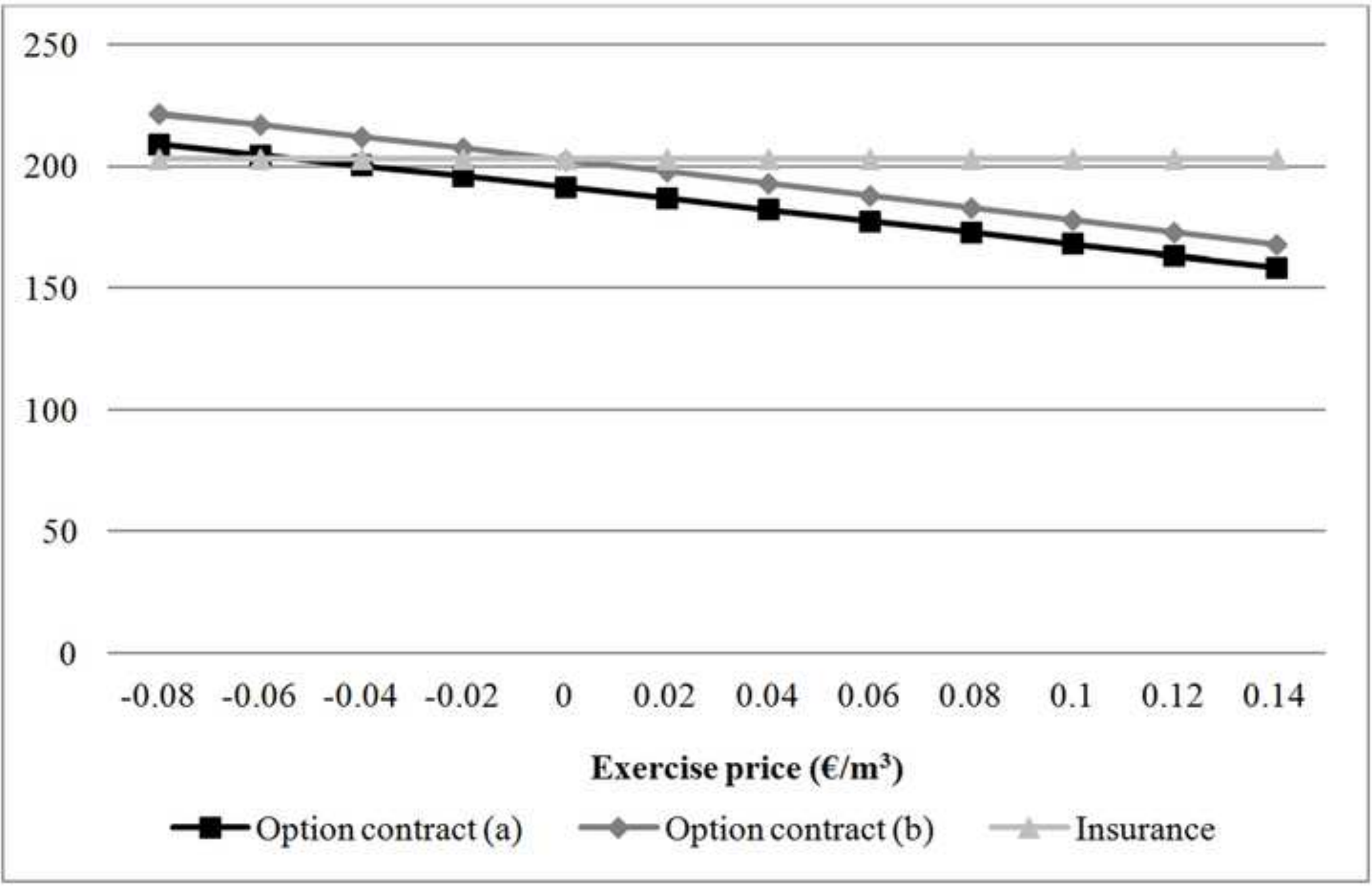




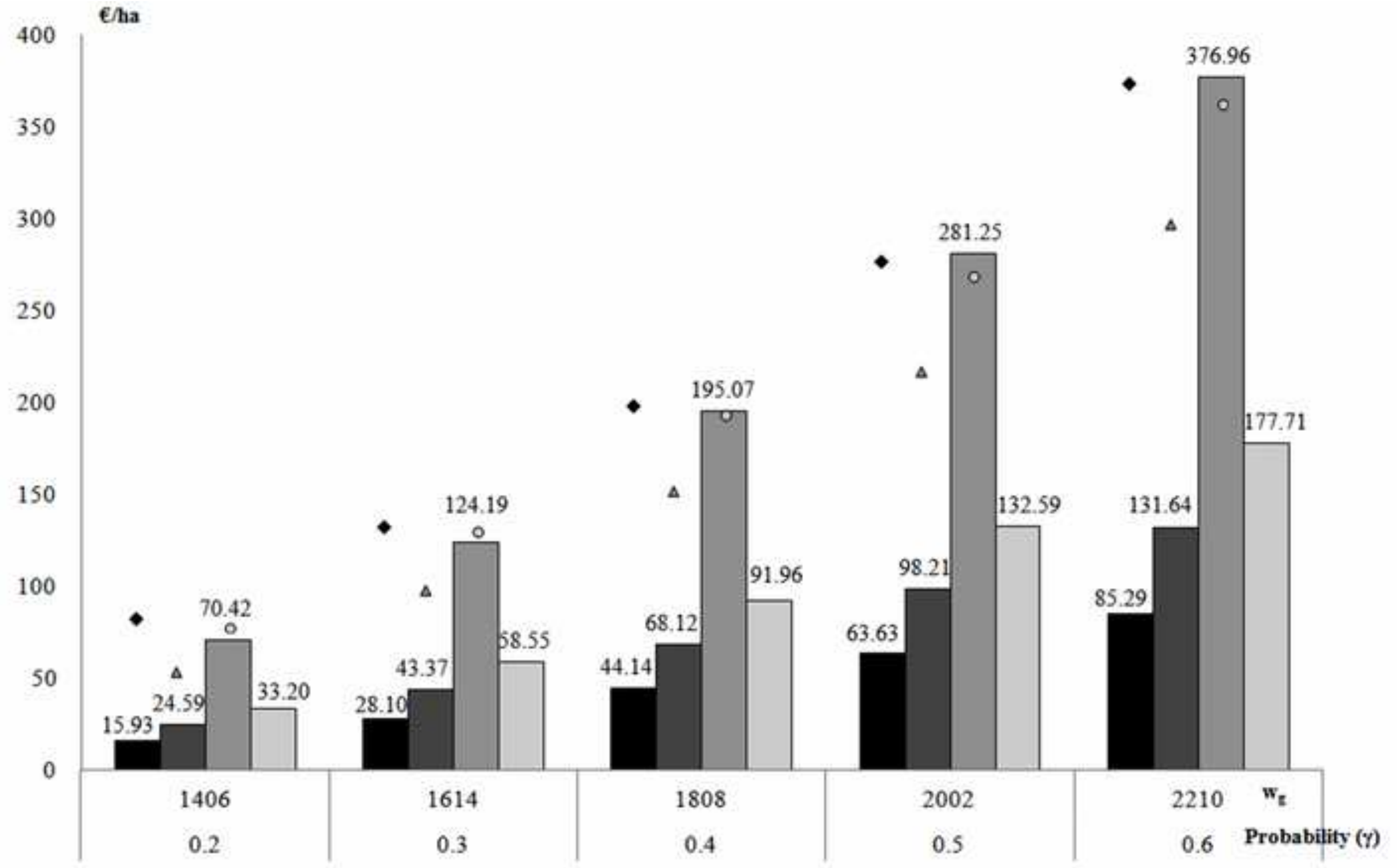

- Option contract price $(\mathrm{Pe}=-0.08) \quad$ aOption contract price $(\mathrm{Pe}=0.12) \quad$ aInsurance price $(\mathrm{b}=0.7)$

- WTP option contract (b) $(\mathrm{Pe}=0.08) \Delta$ WTP option contract (b) $(\mathrm{Pe}=0.12)$ OWTP insurance 